\title{
The geology of the Kerwan quadrangle of dwarf planet Ceres: Investigating Ceres' oldest, largest impact basin
}

\author{
David A. Williams ${ }^{a, *}$, T. Kneissl ${ }^{b}$, A. Neesemann ${ }^{b}$, S.C. Mest ${ }^{c}$, E. Palomba ${ }^{d}$, T. Platz ${ }^{e}$, \\ A. Nathues ${ }^{e}$, A. Longobardo ${ }^{d}$, J.E.C. Scully ${ }^{f}$, A. Ermakov ${ }^{g}$, R. Jaumann ${ }^{\text {h}}$, D.L. Buczkowski ${ }^{i}$, \\ M. Schäfer ${ }^{\mathrm{e}}$, G. Thangjam ${ }^{\mathrm{e}}$, C.M. Pieters ${ }^{\mathrm{j}}$, T. Roatsch ${ }^{\mathrm{h}}$, F. Preusker ${ }^{\mathrm{h}}$, S. Marchi ${ }^{\mathrm{k}}$, \\ N. Schmedemann ${ }^{c}$, H. Hiesinger ${ }^{1}$, A. Frigeri ${ }^{d}$, C.A. Raymond ${ }^{\mathrm{f}}$, C.T. Russell ${ }^{\mathrm{m}}$ \\ a School of Earth E' Space Exploration, Arizona State University, Tempe, AZ 85287-1404 USA \\ ${ }^{\mathrm{b}}$ Freie Universität, Berlin, Germany \\ c Planetary Science Institute, Tucson, AZ USA \\ ${ }^{\mathrm{d}}$ National Institute of Astrophysics, Rome, Italy \\ e Max Planck Inst. for Solar System Research, Göttingen, Germany \\ NASA Jet Propulsion Laboratory, California Institute of Technology, Pasadena, CA, USA \\ ${ }^{\mathrm{g}}$ Massachusetts Institute of Technology, Cambridge, MA USA \\ h DLR, Berlin, Germany \\ i Johns Hopkins University Applied Physics Laboratory, Laurel, MD, USA \\ ${ }^{\mathrm{j}}$ Brown University, Providence, RI, USA \\ ${ }^{\mathrm{k}}$ Southwest Research Institute, Boulder, CO, USA \\ ${ }^{1}$ Institute for Planetology, Westfälische Wilhelms-University, Münster, Germany \\ ${ }^{\mathrm{m}}$ UCLA, Los Angeles, CA, USA
}

\section{A R T I C L E I N F O}

\section{Article history:}

Received 21 September 2016

Revised 25 July 2017

Accepted 7 August 2017

Available online 12 August 2017

\begin{abstract}
A B S T R A C T
We conducted a geologic mapping investigation of Dawn spacecraft data to determine the geologic history of the Kerwan impact basin region of dwarf planet Ceres, which is mostly located in the Ac-7 Kerwan Quadrangle. Geological mapping was applied to Dawn Framing Camera images from the Low Altitude Mapping Orbit (LAMO, $35 \mathrm{~m} /$ pixel) and supplemented by digital terrain models and color images from the High Altitude Mapping Orbit (HAMO, $135 \mathrm{~m} /$ pixel), as well as preliminary Visible and Infrared Spectrometer (VIR) and gravity data. The 284-km diameter Kerwan impact basin is the oldest unequivocal impact crater on Ceres, and has a highly discontinuous, polygonal, degraded rim and contains a 'smooth' unit that both fills the basin floor and surrounds the degraded rim to the west, south, and east. Although there are some subtle topographic features in the Kerwan basin that could be interpreted as flow boundaries, there is no indisputable evidence of cryovolcanic features in or around the basin (however if such features existed they could be buried). Nevertheless, all data point to impact-induced melting of a cerean crust enriched in a volatile, likely water ice, to produce the Kerwan smooth material. Subsequent geologic activity in this region includes emplacement of impact craters such as Dantu, which produced a variety of colorful deposits, and rayed craters such as Rao and Cacaguat. Based on the crater size-frequency distribution absolute model ages of the Kerwan smooth material in and around the basin, marking a minimum age for the Kerwan basin, our mapping defines this as the oldest boundary within the cerean geologic timescale, separating the Pre-Kerwanan and Kerwanan Periods at $>1.3$ Ga (Lunarderived chronology model) or $>230-850 \mathrm{Ma}$ (Asteroid-derived chronology model, depending on strength of target material).
\end{abstract}

(c) 2017 Elsevier Inc. All rights reserved.

\section{Introduction}

As part of NASA's Dawn mission at dwarf planet Ceres (Russell, 2004), the Dawn Science Team established a geologic mapping

\footnotetext{
* Corresponding author.

E-mail address: David.Williams@asu.edu (D.A. Williams).
}

campaign for Ceres, the justification of which was to provide geologic context for analysis of surface features identified in Framing Camera (FC: Sierks et al., 2011) images, and for interpretation of compositional information from the Visible and Infrared spectrometer (VIR: De Sanctis et al., 2011), the Gamma Ray and Neutron Detector (GRaND: Prettyman et al., 2011) and gravity data from the radio-science experiment (Park et al., 2016) during the 


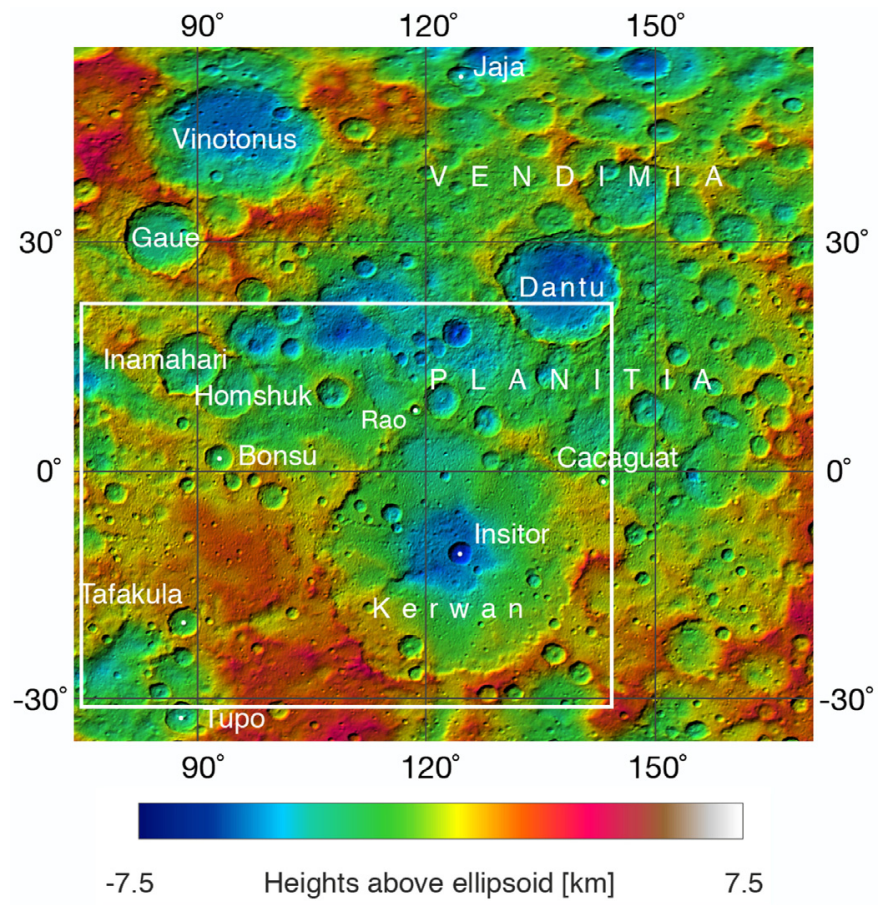

Fig. 1. Dawn FC HAMO-based stereo digital terrain model (DTM) of the Vendimia Planitia region of Ceres, containing the Kerwan impact basin and Dantu crater. White box outlines our geologic mapping region including the Kerwan quadrangle and part of the Toharu quadrangle. For details on DTM production, see Preusker et al. (2016).

Nominal Mission. This geologic mapping campaign includes production of global geologic maps at Survey (Buczkowski et al., 2016) and HAMO resolutions (Mest et al., 2017a) to define Ceres global geologic history, as well as a series of quadrangle geologic maps at LAMO resolution (Williams et al., 2017; Introductory paper, this issue) to identify detailed geologic relations of key areas of Ceres. In this paper we discuss the geology of the Ac-7 Kerwan Quadrangle, and how our 1:500 K geological map has aided understanding the geologic history of the Kerwan basin region of Ceres.

\section{Regional setting}

The 284-km diameter Kerwan impact basin (center $10.77^{\circ} \mathrm{S}$, $123.99^{\circ} \mathrm{E}$ ) is the largest indisputable impact crater on Ceres, and was first imaged in Dawn's Approach images obtained in spring of 2015. Kerwan (named after the Hopi spirit of the sprouting maize) was initially interpreted as the oldest crater on Ceres, based on several lines of evidence: 1) the degradation state of its rim (Bland et al., 2016; Hiesinger et al., 2016); 2) the lack of any larger, definitive impact craters (Marchi et al., 2016); 3) preliminary crater size-frequency distribution measurements of 'smooth' material in and surrounding the Kerwan basin, indicating it is the oldest unit outside of the 'cratered terrain' that makes up most of Ceres' crust (Hiesinger et al., 2016); and 4) modeling suggesting that the Kerwan basin has undergone considerable viscous relaxation compared to Ceres smaller craters, suggestive of advanced age (Bland et al., 2016). Kerwan is located in Ceres' eastern hemisphere, within a larger topographic low named Vendimia Planitia (Marchi et al., 2016) that contains both Kerwan and Dantu craters (Fig. 1). The Kerwan region stood out in Dawn's low-resolution images because a 'smooth material' appeared to fill the basin floor and immediate surroundings to the west and east, as shown in the Survey-based map (Buczkowski et al., 2016). The recognition of this smooth material in and around the Kerwan basin suggested the Kerwan impact initiated a resurfacing event, either by impact melting or cryovolcanism (Buczkowski et al., 2016; Hiesinger et al., 2016; Mest et al., 2017b). Thus, one of the goals of the present higher resolution, LAMO-based mapping is to seek geological evidence of any features that might suggest one or another of these processes for the formation of this 'smooth terrain' . Additionally, the Kerwan basin is partially covered by ejecta from Dantu crater to the north. Dantu crater $\left(125-\mathrm{km}\right.$ diameter, $\left.24.3^{\circ} \mathrm{N}, 138.23^{\circ} \mathrm{E}\right)$ has produced ejecta that displays a variety of colors in the color ratio composite images of the Framing Camera. Dantu crater is located at a longitude where Küppers et al. (2014) suggested water vapor was being released from Ceres, based on ESA Herschel space telescope observations. A discussion of the geology of Dantu crater is given in Kneissl et al. (2016), and the Dantu Quadrangle geologic map is included as supplemental online material with the Introductory paper (Williams et al., 2017; this issue).

\section{Methods}

The overall description of our mapping approach, base map and supplemental materials, and coordinate system and other technical issues are discussed in the introductory paper (Williams et al., 2017; this issue). Briefly, the Ac-7 Kerwan Quadrangle was iteratively mapped using successively higher spatial resolution Framing Camera image mosaics obtained during the various phases of the Dawn mission: Survey ( $415 \mathrm{~m} / \mathrm{pixel})$, High Altitude Mapping Orbit (HAMO, $\sim 140 \mathrm{~m} / \mathrm{pixel}$ ), and Low Altitude Mapping Orbit ( $\sim 35 \mathrm{~m} /$ pixel). Stereophotogrammetry-based digital terrain models (DTMs) were provided by DLR, including both an early Survey DTM and a HAMO DTM (to which the LAMO mosaic was registered: see Preusker et al., 2016). Supplemental materials provided by the Dawn Science Team to aid in the mapping and interpretations included photometrically corrected HAMO mosaics, and enhanced color and color ratio composite image mosaics. All Dawn image base maps, DTMs, and supplemental images, including the maps and figures herein, are presented in the IAU-approved Kait coordinate system (Roatsch et al., 2016) unless otherwise noted.

\section{Results}

Fig. 2a-d shows the LAMO base map, DTM, photometrically corrected mosaic, and color ratio composite (CRC) mosaics for the Kerwan map region, respectively, and Fig. 3a-b show our geological map and map legend for the Kerwan basin region. Because the Kerwan basin also crosses into Ac-12 Toharu Quadrangle, our discussion henceforth will cover the whole of the Kerwan basin region, irrespective of quadrangle boundaries (although those boundaries are shown in Fig. 2a-d). The Kerwan Quadrangle itself is located between $-22-22^{\circ}$ and $72-144^{\circ} \mathrm{E}$. As stated in the 'Geologic Setting' (Section 2), this quadrangle is dominated by the $284-\mathrm{km}$ diameter impact basin Kerwan, whose rim is polygonal and degraded and whose interior has been filled with a smooth material that hosts a significantly lower impact crater density than most of the rest of Ceres' surface (Buczkowski et al., 2016; Hiesinger et al., 2016). This smooth material clearly extends beyond Kerwan to the west and east, and the geologic maps in Buczkowski et al. (2016) and Mest et al. (2017a) based on Survey and HAMO images, respectively, show this unit extending for several hundred kilometers around the basin. Remapping this area using LAMO images and HAMO topography suggests that the smooth material is both more heavily cratered and less extensive than we thought based on Survey images. To the north of Kerwan is the $125-\mathrm{km}$ diameter crater Dantu, whose ejecta field covers the NE corner of this quadrangle. Framing Camera color data show that the Dantu ejecta displays multiple colors but is dominated by blue, which is distinct from the Kerwan smooth material suggesting excavation of materials of 
a

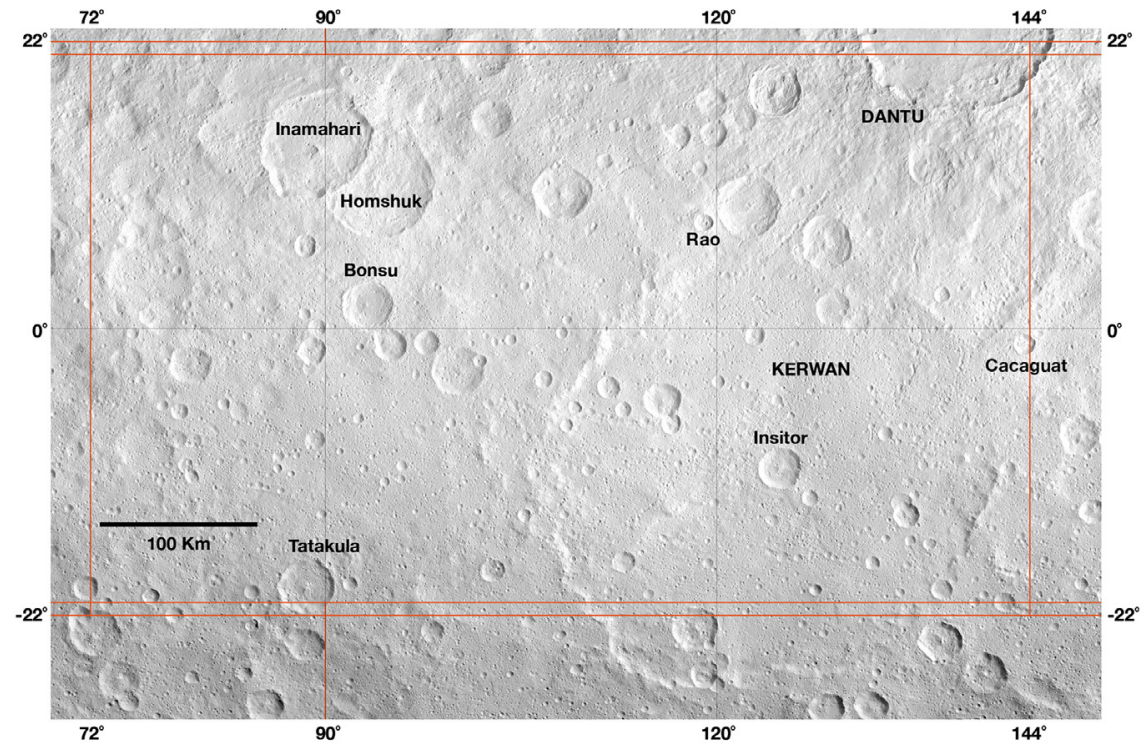

b

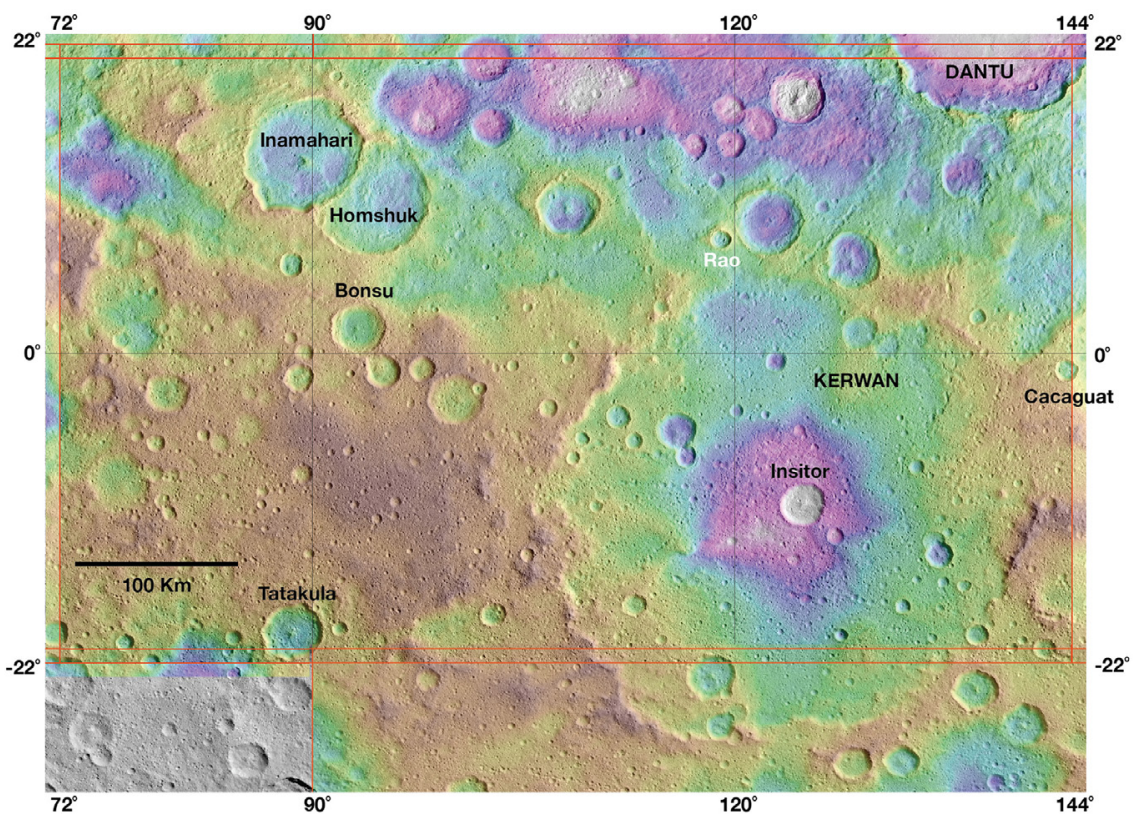

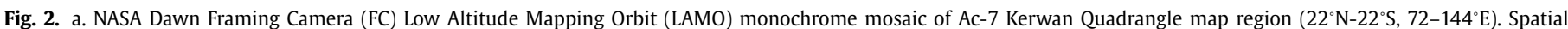

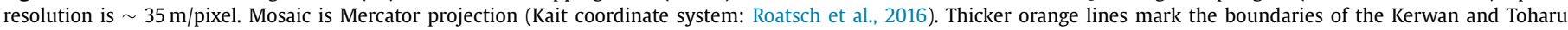

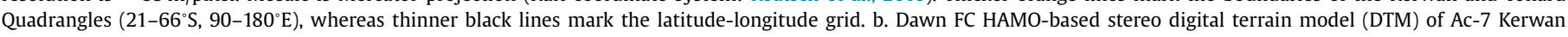

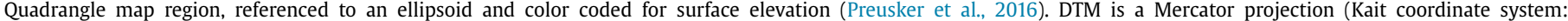

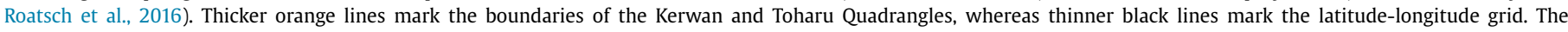

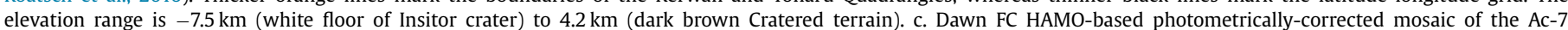

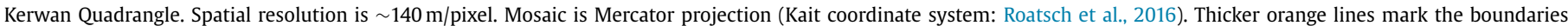

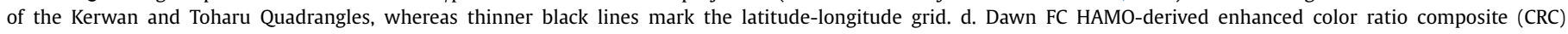

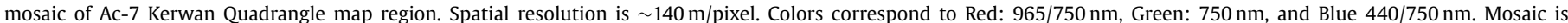

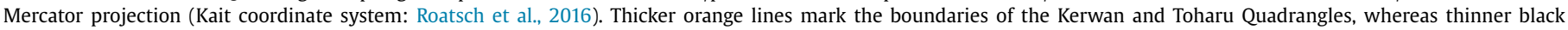
lines mark the latitude-longitude grid.

different compositions than Kerwan. The western portion of this quadrangle contains a heavily cratered terrain that appears to be the most common unit on Ceres surface. Superposed on this older cratered terrain are the paired craters Inamahari $(68-\mathrm{km}$ diameter, $\left.14.13^{\circ} \mathrm{N}, 89.22^{\circ} \mathrm{E}\right)$ and Homshuk (70-km diameter, $\left.11.23^{\circ} \mathrm{N}, 94.06^{\circ} \mathrm{E}\right)$, and superposed on their ejecta blanket is the $31-\mathrm{km}$ diameter crater Bonsu $\left(1.74^{\circ} \mathrm{N}, 93.21^{\circ} \mathrm{E}\right)$. Bonsu contains a smooth floor unit that has a slightly lower albedo $(\sim 0.09)$ than the other units in the quadrangle $(\sim 0.09-0.1)$, except for Tafakula crater $(\sim 0.08-0.09)$ and the dark diffuse material (also $\sim 0.08-0.09$ ) covering parts of the Dantu ejecta. There are two craters with bright ejecta blankets that are interpreted to be fresh (young): Rao (12 km diameter, $\left.8.1^{\circ} \mathrm{N}, 119.01^{\circ} \mathrm{E}\right)$, and Cacaguat ( $13 \mathrm{~km}$ diameter, $\left.1.19^{\circ} \mathrm{S}, 143.57^{\circ} \mathrm{E}\right)$.

\subsection{Description of map units}

In this section we give the Description of Map Units (DOMU) for the Kerwan basin map region. Fig. 4 shows the type examples of our geologic map units, referenced to the latitudes-longitudes 

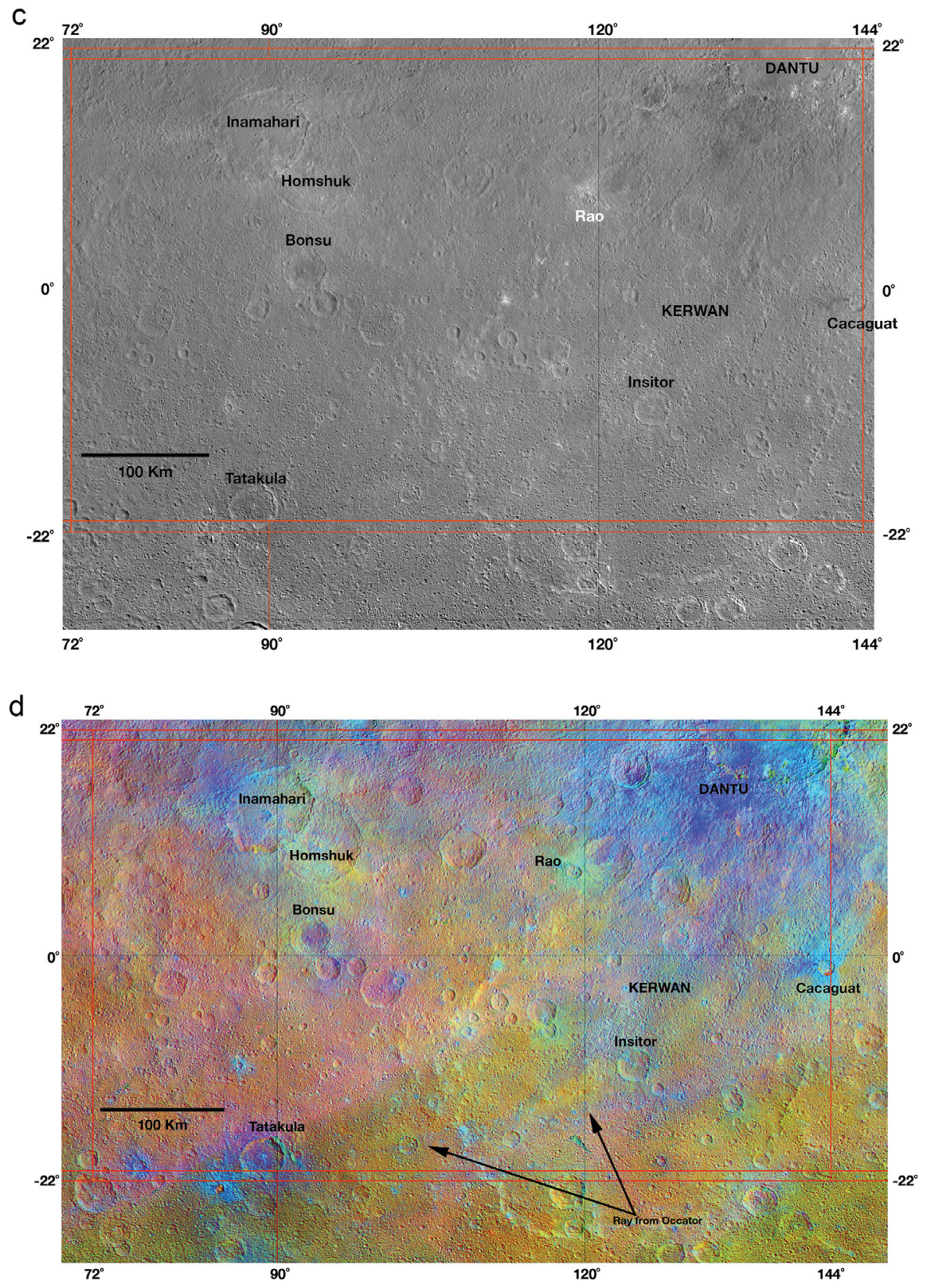

Fig. 2. Continued

discussed in the sections below. Fig. 5 shows the crater count areas for major geologic units included in our map.

\subsubsection{Cratered terrain (crt, RGB color: 125-63-0)}

Description: Most widespread unit on Ceres. Generally lowalbedo ( 0.08-0.1) with some minor variability, heavily cratered at all crater sizes, with crater shapes changing from round to polygonal. Crater rims range from well preserved to those that can barely be discerned. Crater floors are usually shallow. DTMs show unit has some relief, with a hilly surface. Framing Camera color ratio composite (CRC) images show some color variations, but in general the composition of the surface does not significantly change from region to region (De Sanctis et al., 2016). Crater counts of this unit (Crater Count Area \#4: Figs. 5, 6; Table 1) suggest an absolute model age (AMA) of $1.98 \pm 0.27$ Ga using the lunar-derived model (LDM) and an age of $0.39 \pm 0.053 \mathrm{Ga}$ to $1.02 \pm 0.14 \mathrm{Ga}$ using the asteroid flux-derived model (ADM, depending on the strength of target material). Type area: $2.7^{\circ} \mathrm{S}, 79.5^{\circ} \mathrm{E}$. Interpretation: Ceres ancient crust, a composite of hydrothermally-altered silicates, including ammoniated phyllosilicates, carbonates, salts, and water ice (De Sanctis et al., 2016), which has been disrupted and altered by superposed impacts from multiple sources over Ceres history. All other units superpose the Cratered terrain (crt).

\subsubsection{Degraded crater rim material (crd, RGB color: 168-56-0)}

Description: Unit consists of isolated peaks, ridges, or chains of topographically high material embayed by the Smooth material (next section), that forms a circular pattern and is identifiable by illumination at low sun angles. Morphologically, this unit is similar to the Cratered terrain, and the unit shows similar albedo and color ranges as found in Cratered terrain. Individual blocks of this unit are too small for application of crater counts for age determination. Type area: $13.7^{\circ} \mathrm{S}, 140.6^{\circ} \mathrm{E}$. Interpretation: Unit makes up the 
a

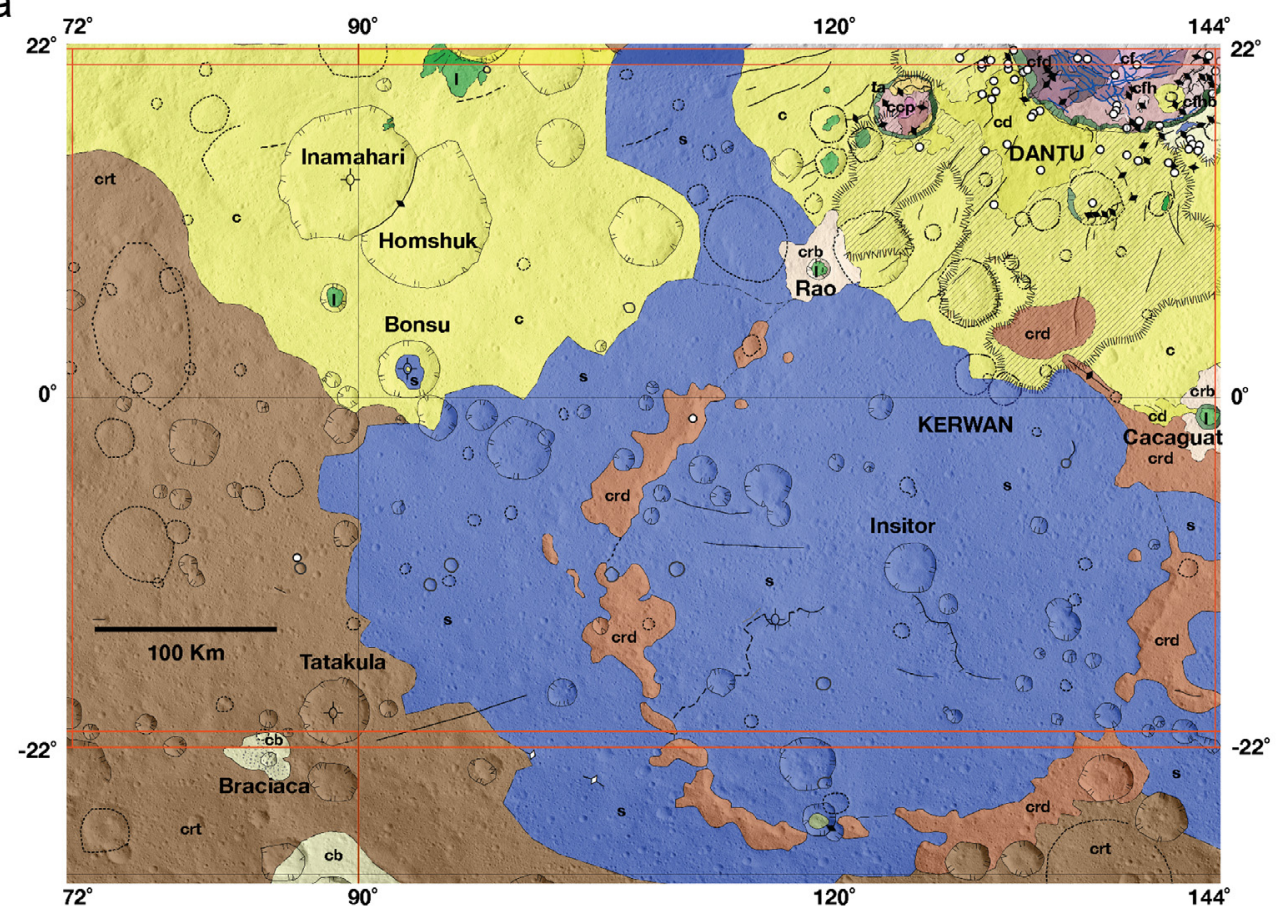

b

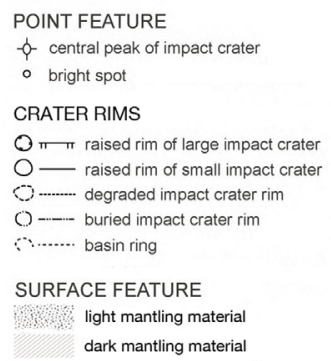

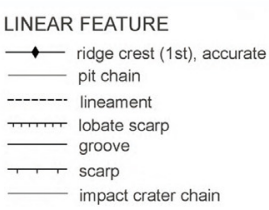

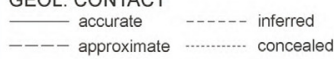

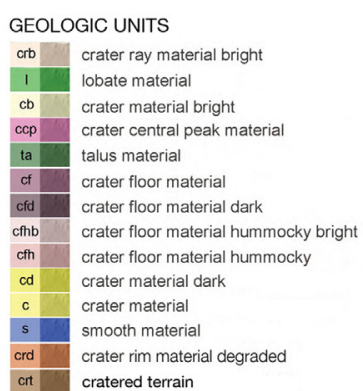

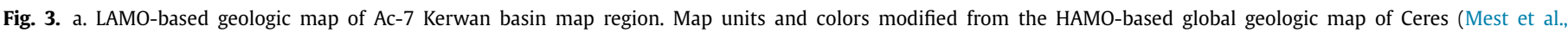
2017). b. Map legend for the Ac-7 Kerwan Quadrangle geologic map shown in Figure 3a.
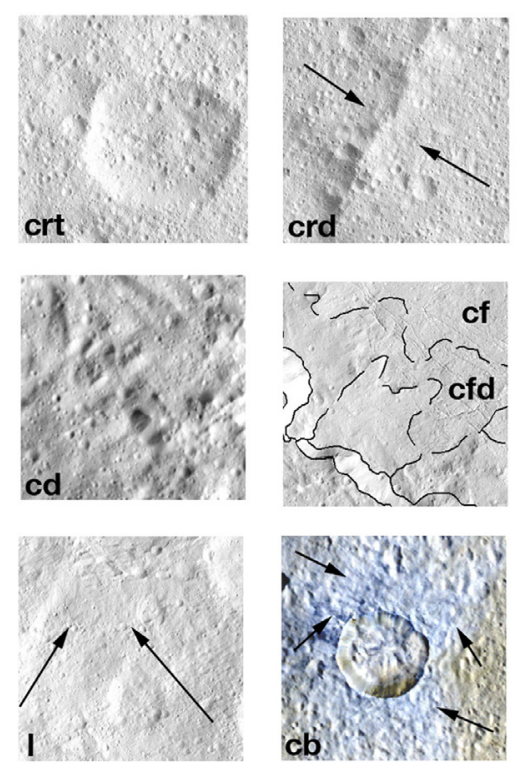
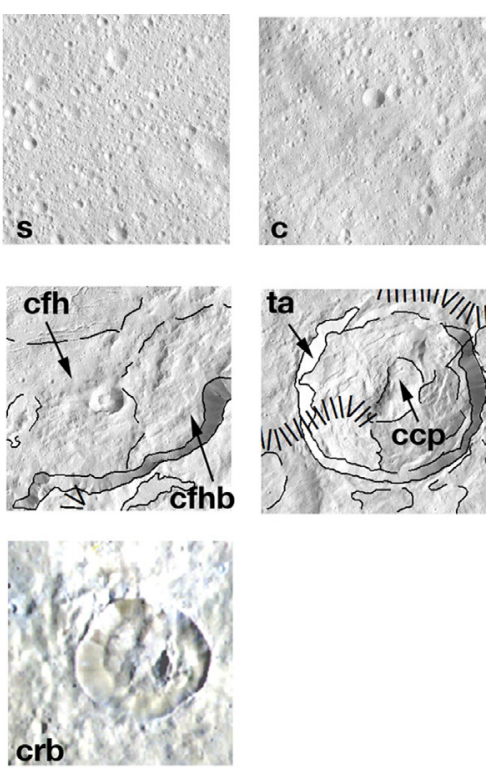

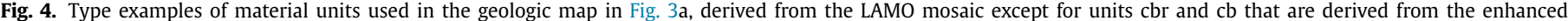

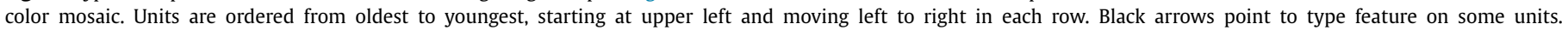
Latitude-longitude locations of these type examples are referenced in the text (Section 4.1 ). Each square is $\sim 70 \mathrm{~km}$ on a side. North is to the top in all images. 


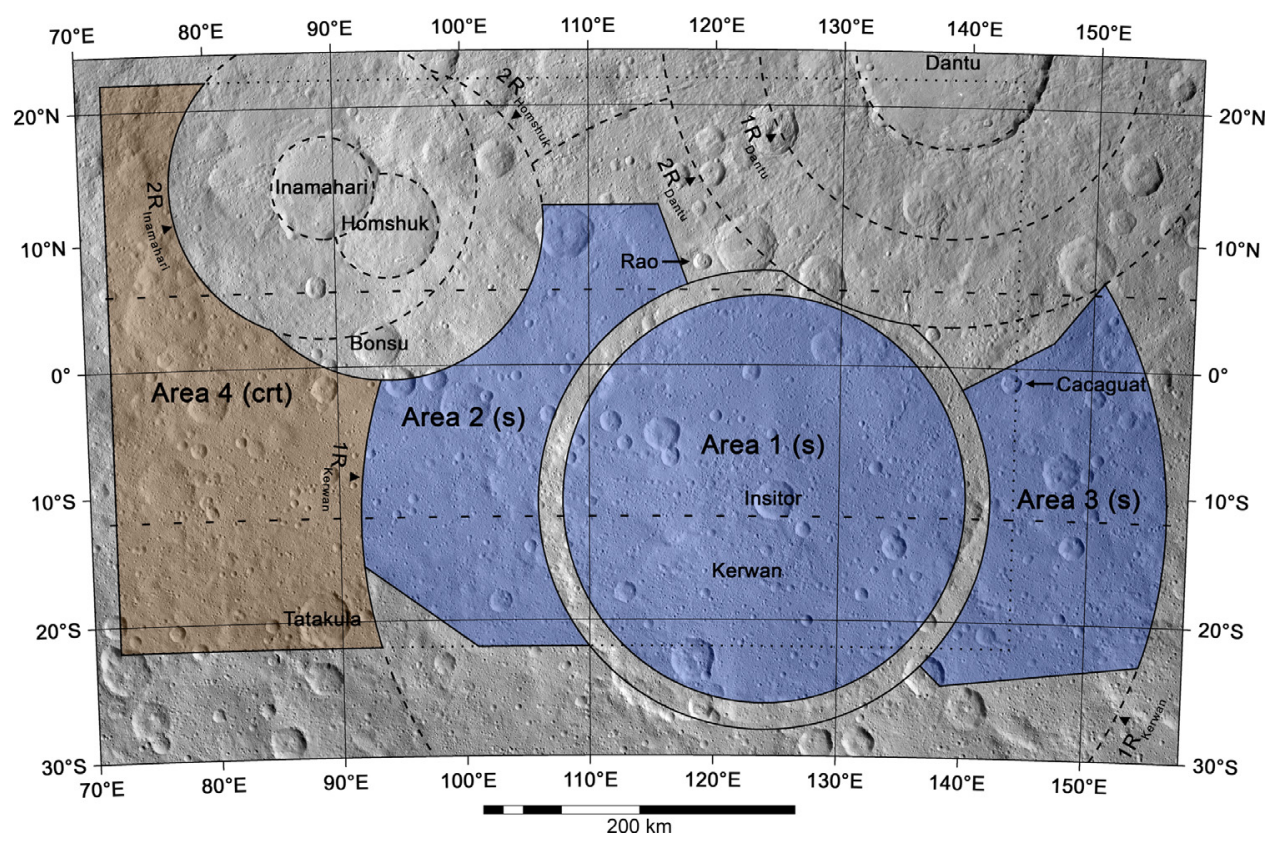

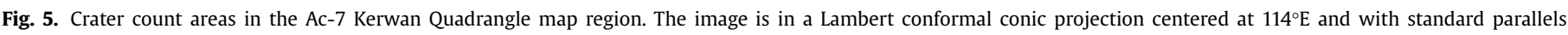
at $6^{\circ} \mathrm{N}$ and $12^{\circ} \mathrm{S}$

remaining visible rim of Kerwan basin, and is composed of ancient, Ceres crust exposed by Kerwan impact event.

\subsubsection{Smooth material (s, RGB color: 0-51-204)}

Description: Unit consists of a cratered surface within and surrounding the Kerwan basin to the west, south, and east that has a lower abundance of larger ( $>50 \mathrm{~km}$ diameter) craters than the Cratered terrain, and in general is less hilly than the Cratered terrain, but with variable relief. Unit shows the same albedo (0.090.11 ) and color variations as the Cratered terrain (although the material within the basin has a greater areal extent of 'yellow' material in the color ratio composite compared to the more orangepink to blue hues in the Cratered terrain). Also clearly visible in the color ratio composite image is a linear bluish feature, trending WSW, that crosses the basin floor and into the Cratered terrain. At LAMO resolution there is no clear evidence of flow fronts, vents, or other structures in this unit outside the Kerwan basin. However, within the Kerwan basin, there are indications of an irregular, discontinuous scarp and pit crater chain that separates the south-central section of the floor from the remainder of the floor (Fig. 8), south of the depressed central region containing the superposed $26-\mathrm{km}$ diameter crater Insitor $\left(10.7^{\circ} \mathrm{S}, 124.9^{\circ} \mathrm{E}\right)$. There is no other clear evidence for flow fronts, vents, or other structures in this unit. Crater counts of the smooth material within the Kerwan basin (Crater Count Area \#1: Figs. 5, 6; Table 1) obtained AMAs of $1.30 \pm 160 \mathrm{Ga}$ (LDM) and $0.24 \pm 0.028 \mathrm{Ga}$ to $0.68 \pm 0.08 \mathrm{Ga}$ (ADM, depending on strength of target material). Counts of the smooth material outside the basin (Crater Count Areas \#2, 3: Figs. 5, 6; Table 1 ) suggest an absolute model age (AMA) of $1.3 \pm 0.079 \mathrm{Ga}$ to $1.36 \pm 0.22 \mathrm{Ga}$ using the lunar-derived model (LDM), and an age of $0.23 \pm 0.014 \mathrm{Ga}$ to $0.85 \pm 0.051 \mathrm{Ga}$ using the asteroid flux-derived model (ADM, depending on strength of target material). Thus, the Smooth material has similar ages whether within or without the Kerwan basin. Gravity data (Konopliv et al., 2017) (Fig. 9) show a positive Bouguer anomaly within the basin (see details of Bouguer anomaly computation in Ermakov et al., 2017), which implies isostatic compensation of the basin. Bland et al. (2016) also found that the Kerwan basin is partly relaxed. This implies that the local, lowdensity crust could have been enriched in volatiles, or that the Ker- wan impact produced a crust with a large impact-induced porosity, which reduced the crustal density in the region. A separate area of Smooth material occurs on the floor of the complex, 31-km diameter crater Bonsu (Fig. $7,1.7^{\circ} \mathrm{N}, 93.2^{\circ} \mathrm{E}$ ), with a level surface surrounding the central peak. The photometrically-corrected HAMO images show that this Bonsu floor unit has a similar albedo as the Smooth material unit around Kerwan. Type area: $4.6^{\circ} \mathrm{S}, 130.1^{\circ} \mathrm{E}$. Interpretation: Impact melt emplaced after the Kerwan impact event. We interpret the irregular, discontinuous scarp and pit-crater chain as a possible flow boundary, but the lack of a distinctive age difference within any part of the Kerwan smooth material, and the lack of identifiable vents (although they could be buried), suggests that the source of any flow material is likely the Kerwan impact itself, and not subsequent cryovolcanism. We interpret the linear bluish feature trending WSW across the Kerwan basin seen in the CRC as a ray from Occator crater (Buczkowski et al., 2017; this issue). The separate smooth floor unit in Bonsu crater we interpret as an accumulation of low-albedo impact melt or cryovolcanic material.

\subsubsection{Crater material (c, RGB color: 255-255-51)}

Description: Unit consists of a less cratered surface compared to Cratered terrain, but more heavily cratered than the Smooth material, located within 1-2 crater diameters of the large impact craters Inamahari-Homshuk and Dantu in this quadrangle. Surface has a morphology ranging from flat to hilly to hummocky, with some changes in albedo and in the color ratio images, i.e., there is a higher albedo SE of Homshuk crater (0.11). Some of these variations could possibly be caused by diffuse material surrounding Dantu crater (Kneissl et al., 2016). Crater counts of the Dantu ejecta blanket (Kneissl et al., 2016) suggest an absolute model age (AMA) of 72-150 Ma using the lunar-derived model and an age of 25-125 Ma using the asteroid flux-derived model. A new analysis of the Dantu ejecta blanket done for this work by A. Neesemann suggests a Dantu formation age (preliminary) of $77.7 \pm 8.0 \mathrm{Ma}$ (LDM) and $22.9 \pm 2.3 \mathrm{Ma}(\mathrm{ADM})$ (Neeseman et al., 2017; in preparation). Type area: $11.3^{\circ} \mathrm{N}, 82.9^{\circ} \mathrm{E}$. Interpretation: Region of continuous ejecta from Inamahari-Homshuk and Dantu impact craters. 

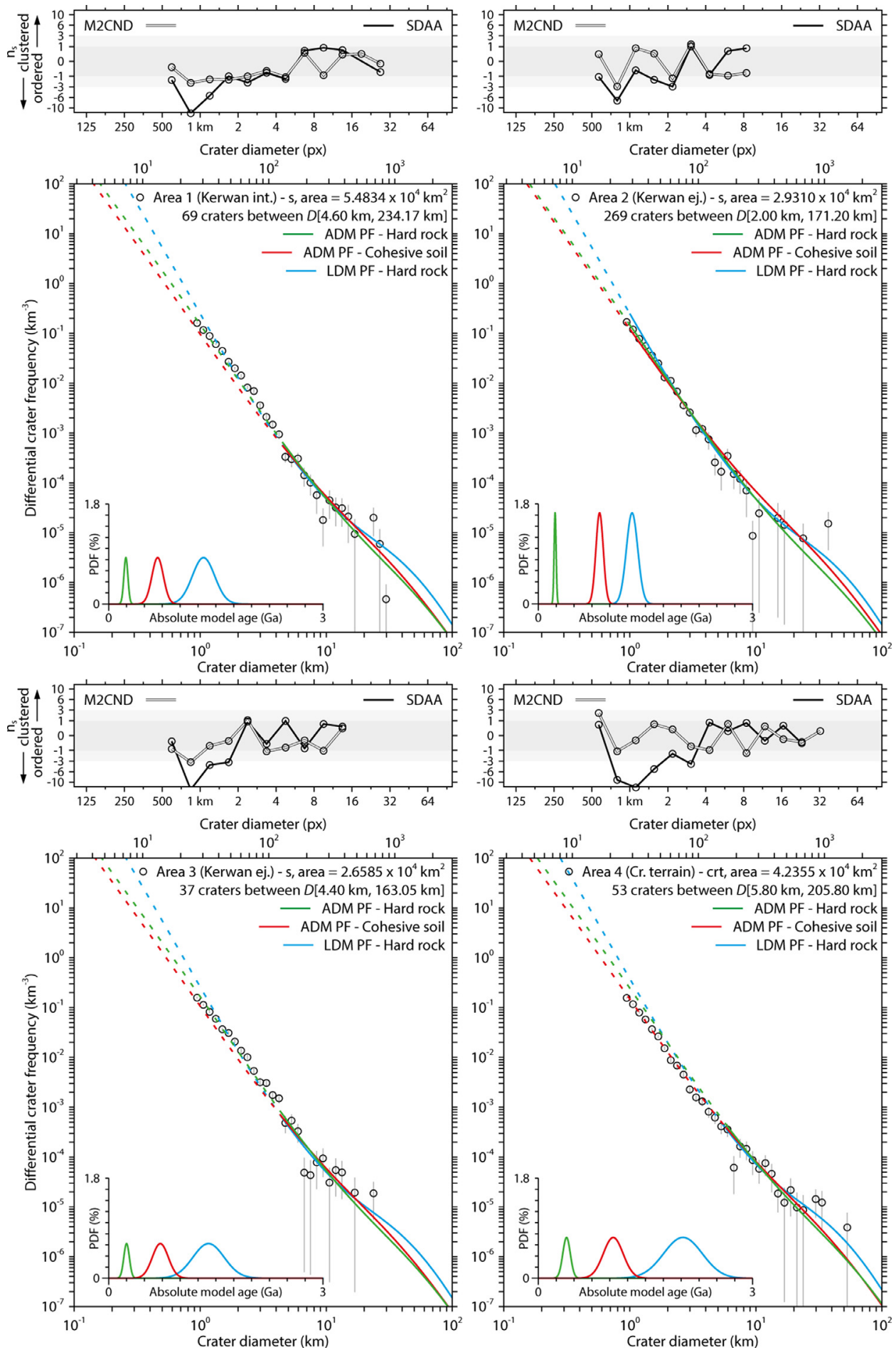

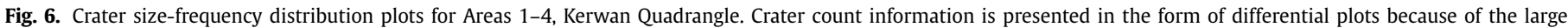

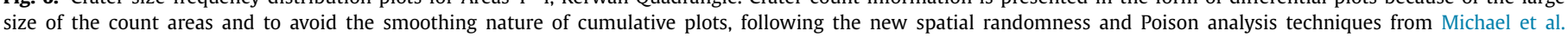

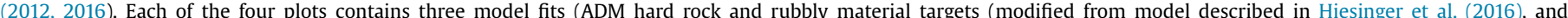

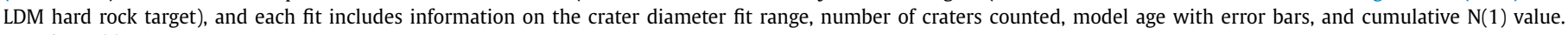
See also Table 1.

\subsubsection{Bright crater material (cb, RGB color: 255-255-179)}

Description: Unit consists of high-albedo material (0.11-0.12) surrounding small impact craters with well-preserved rims, suggestive of their youth. Unit is most easily visible in enhanced color and color ratio images. In the color ratio composite, this unit appears dark blue and stands out from its surroundings. Type area: $2.0^{\circ} \mathrm{S}, 140.0^{\circ} \mathrm{E}$. Interpretation: Impact ejecta originating from rela- tively young impact craters. The dark blue color in color ratio images is suggestive of either a distinct composition or immaturity of the regolith.

4.1.6. Bright crater ray material (crb, RGB color: 255-222-189)

Description: This unit consists of high-albedo material (0.12), which separately extends from the $12-\mathrm{km}$ diameter, moderately 
Table 1

A). Crater count results for geologic map units in the Ac-7 Kerwan quadrangle using the lunar-derived chronology model.

\begin{tabular}{|c|c|c|c|c|c|c|c|c|}
\hline & & & & & LDM & $(\mathrm{HR})$ & & \\
\hline Unit name & Geo unit & Label & $\begin{array}{l}\text { Count area } \\
\left(\mathrm{km}^{2}\right)\end{array}$ & $\begin{array}{l}\text { AMA } \\
\text { (Ma) }\end{array}$ & Error (Ma) & $\begin{array}{l}\text { N_cum(1) } \\
\left(\mathrm{km}^{-2}\right)\end{array}$ & $\begin{array}{l}\text { \# of } \\
\text { fitted } \\
\text { craters }\end{array}$ & Fit range $(\mathrm{km})$ \\
\hline Rao crater & $\begin{array}{l}\text { crater ray material } \\
\text { bright }\end{array}$ & crb & 283.18 & 33.3 & $+2.5 /-2.5$ & $1.94 \mathrm{E}-03$ & 173 & $0.18-0.63(16.82)$ \\
\hline Rao crater & lobate material & 1 & 40.44 & 20.2 & $+3.4 /-3.4$ & $1.18 \mathrm{E}-03$ & 34 & $0.14-0.45(6.36)$ \\
\hline Cacaguat crater & $\begin{array}{l}\text { crater ray material } \\
\text { bright }\end{array}$ & $\mathrm{crb}$ & 349.26 & 3.29 & $+0.59 /-0.59$ & $1.92 \mathrm{E}-04$ & 31 & $0.16-0.50(18.69)$ \\
\hline Cacaguat crater & lobate material & 1 & 67.81 & 1.3 & $+0.79 /-0.56$ & $7.60 \mathrm{E}-05$ & 3 & $0.14-0.18(8.23)$ \\
\hline $\begin{array}{l}\text { Area } 1 \text { (Kerwan } \\
\text { interior) }\end{array}$ & smooth material & s & $54,834.09$ & 1,307 & $+156 /-156$ & 7.63E-02 & 69 & $4.60-32.00(234.17)$ \\
\hline $\begin{array}{l}\text { Area } 2 \text { (W Kerwan } \\
\text { smooth unit) }\end{array}$ & smooth material & $\mathrm{s}$ & $29,310.61$ & 1,306 & $+79 /-79$ & $7.62 \mathrm{E}-02$ & 269 & $2.00-35.00(171.20)$ \\
\hline $\begin{array}{l}\text { Area } 3 \text { (E Kerwan } \\
\text { smooth unit) }\end{array}$ & smooth material & $s$ & $26,585.16$ & 1,360 & $+220 /-220$ & 7.94E-02 & 37 & $4.40-25.00(163.05)$ \\
\hline Area 4 (W cratered & cratered terrain & crt & $42,354.72$ & 1,985 & $+270 /-270$ & $1.16 \mathrm{E}-01$ & 53 & $5.80-55.00(205.80)$ \\
\hline
\end{tabular}

terrain)

B). Crater count results for geologic map units in the Ac-7 Kerwan quadrangle using the asteroid-derived chronology model.

\begin{tabular}{|c|c|c|c|c|c|c|c|c|c|c|c|c|c|}
\hline & & & & & & ADM & (HR) & & & & ADM & $(\mathrm{RM})$ & \\
\hline Unit name & Geo unit & Label & $\begin{array}{l}\text { Count area } \\
\left(\mathrm{km}^{2}\right)\end{array}$ & AMA (Ma) & Error (Ma) & $\begin{array}{l}\text { N_cum(1) } \\
\left(\mathrm{km}^{-2}\right)\end{array}$ & $\begin{array}{l}\text { \# of } \\
\text { fitted } \\
\text { craters }\end{array}$ & $\begin{array}{l}\text { Fit range } \\
(\mathrm{km})\end{array}$ & $\begin{array}{l}\text { AMA } \\
\text { (Ma) }\end{array}$ & Error (Ma) & $\begin{array}{l}\text { N_cum(1) } \\
\left(\mathrm{km}^{-2}\right)\end{array}$ & $\begin{array}{l}\text { \# of } \\
\text { fitted } \\
\text { craters }\end{array}$ & $\begin{array}{l}\text { Fit range } \\
(\mathrm{km})\end{array}$ \\
\hline Rao crater & $\begin{array}{l}\text { crater ray } \\
\text { material } \\
\text { bright }\end{array}$ & crb & 283.18 & 30.4 & $+2.3 /-2.3$ & $7.28 \mathrm{E}-03$ & 173 & $\begin{array}{l}0.18-0.63 \\
(16.82)\end{array}$ & 133 & $+10.08 /-10.08$ & & 173 & $\begin{array}{l}0.18-0.63 \\
(16.82)\end{array}$ \\
\hline Rao crater & $\begin{array}{l}\text { lobate } \\
\text { material }\end{array}$ & 1 & 40.44 & 22.2 & $+3.8 /-3.8$ & $5.29 \mathrm{E}-03$ & 34 & $\begin{array}{l}0.14-0.45 \\
(6.36)\end{array}$ & 97 & $+16.5 /-16.5$ & & 34 & $\begin{array}{l}0.14-0.45 \\
(6.36)\end{array}$ \\
\hline $\begin{array}{l}\text { Cacaguat } \\
\text { crater }\end{array}$ & $\begin{array}{l}\text { crater ray } \\
\text { material } \\
\text { bright }\end{array}$ & $\mathrm{crb}$ & 349.26 & 3.29 & $+0.59 /-0.59$ & 7.84E-04 & 31 & $\begin{array}{l}0.16-0.50 \\
(18.69)\end{array}$ & 14.4 & $+2.57 /-2.57$ & & 31 & $\begin{array}{l}0.16-0.50 \\
(18.69)\end{array}$ \\
\hline $\begin{array}{l}\text { Cacaguat } \\
\text { crater }\end{array}$ & $\begin{array}{l}\text { lobate } \\
\text { material }\end{array}$ & 1 & 67.81 & 1.43 & $+0.87 /-0.61$ & $3.41 \mathrm{E}-04$ & 3 & $\begin{array}{l}0.14-0.18 \\
(8.23)\end{array}$ & 6.26 & $+3.80 /-2.67$ & & 3 & $\begin{array}{l}0.14-0.18 \\
(8.23)\end{array}$ \\
\hline $\begin{array}{l}\text { Area } 1 \\
\text { (Kerwan } \\
\text { interior) }\end{array}$ & $\begin{array}{l}\text { smooth } \\
\text { material }\end{array}$ & s & $54,834.09$ & 236 & $+28 /-28$ & $5.66 \mathrm{E}-02$ & 69 & $\begin{array}{l}4.60-32.00 \\
(234.17)\end{array}$ & 675 & $+80 /-80$ & $3.83 \mathrm{E}-02$ & 69 & $\begin{array}{l}4.60-32.00 \\
(234.17)\end{array}$ \\
\hline $\begin{array}{l}\text { Area } 2 \text { (W } \\
\text { Kerwan } \\
\text { smooth } \\
\text { unit) }\end{array}$ & $\begin{array}{l}\text { smooth } \\
\text { material }\end{array}$ & $\mathrm{s}$ & $29,310.61$ & 233 & $+14 /-14$ & 5.59E-02 & 269 & $\begin{array}{l}2.00-35.00 \\
(171.20)\end{array}$ & 853 & $+51 /-51$ & $4.86 \mathrm{E}-02$ & 269 & $\begin{array}{l}2.00-35.00 \\
(171.20)\end{array}$ \\
\hline $\begin{array}{l}\text { Area } 3 \text { (E } \\
\text { Kerwan } \\
\text { smooth } \\
\text { unit) }\end{array}$ & $\begin{array}{l}\text { smooth } \\
\text { material }\end{array}$ & s & $26,585.16$ & 244 & $+39 /-39$ & $5.82 \mathrm{E}-02$ & 37 & $\begin{array}{l}4.40-25.00 \\
(163.05)\end{array}$ & 704 & $+113 /-113$ & $4.24 \mathrm{E}-02$ & 37 & $\begin{array}{l}4.40-25.00 \\
(163.05)\end{array}$ \\
\hline $\begin{array}{l}\text { Area } 4 \text { (W } \\
\text { cratered } \\
\text { terrain) }\end{array}$ & $\begin{array}{l}\text { cratered } \\
\text { terrain }\end{array}$ & crt & $42,354.72$ & 387 & $+53 /-53$ & $9.28 \mathrm{E}-02$ & 53 & $\begin{array}{l}5.80-55.00 \\
(205.80)\end{array}$ & 1,028 & $+139 /-139$ & $5.84 \mathrm{E}-02$ & 53 & $\begin{array}{l}5.80-55.00 \\
(205.80)\end{array}$ \\
\hline
\end{tabular}

Notes: $\mathrm{AMA}=$ Absolute model age; LDM = Lunar-derived chronology model (Hiesinger et al., 2016); ADM=Asteroid-derived chronology model (modified from Hiesinger et al., 2016); HR=model ages derived for hard rock target; $\mathrm{RM}=$ model ages derived for rubbly material target.

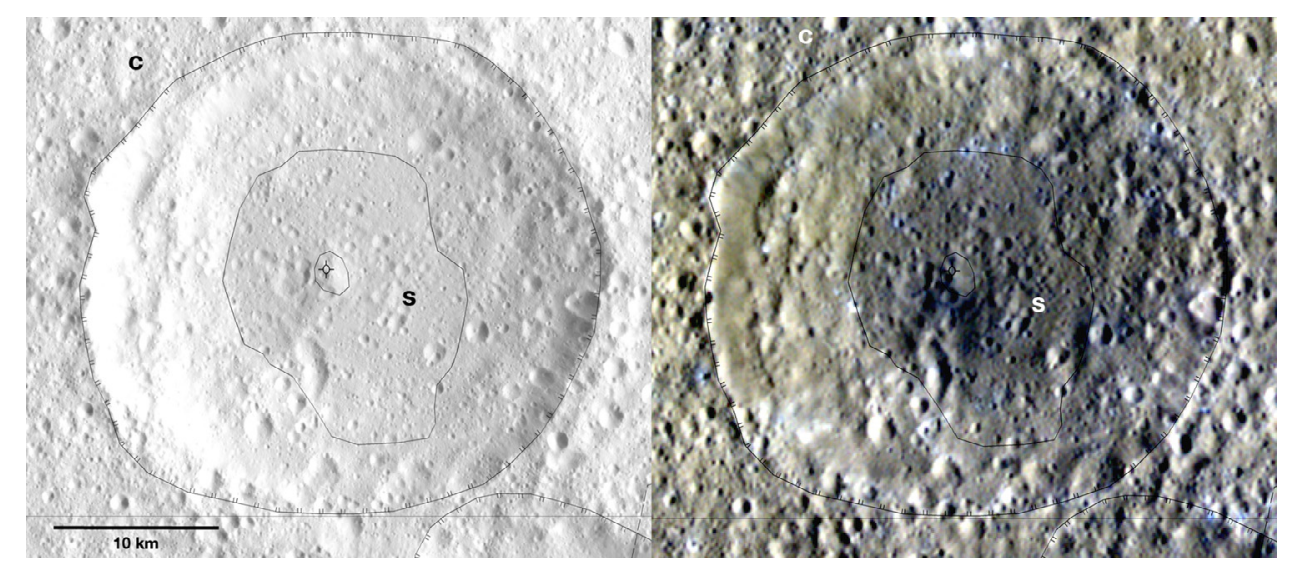

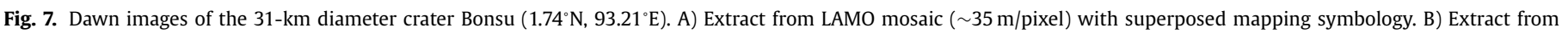
HAMO enhanced color mosaic (Red: $965 \mathrm{~nm}$; Green: $555 \mathrm{~nm}$; Blue: $440 \mathrm{~nm}, 140 \mathrm{~m} /$ pixel) with superposed mapping symbology. 


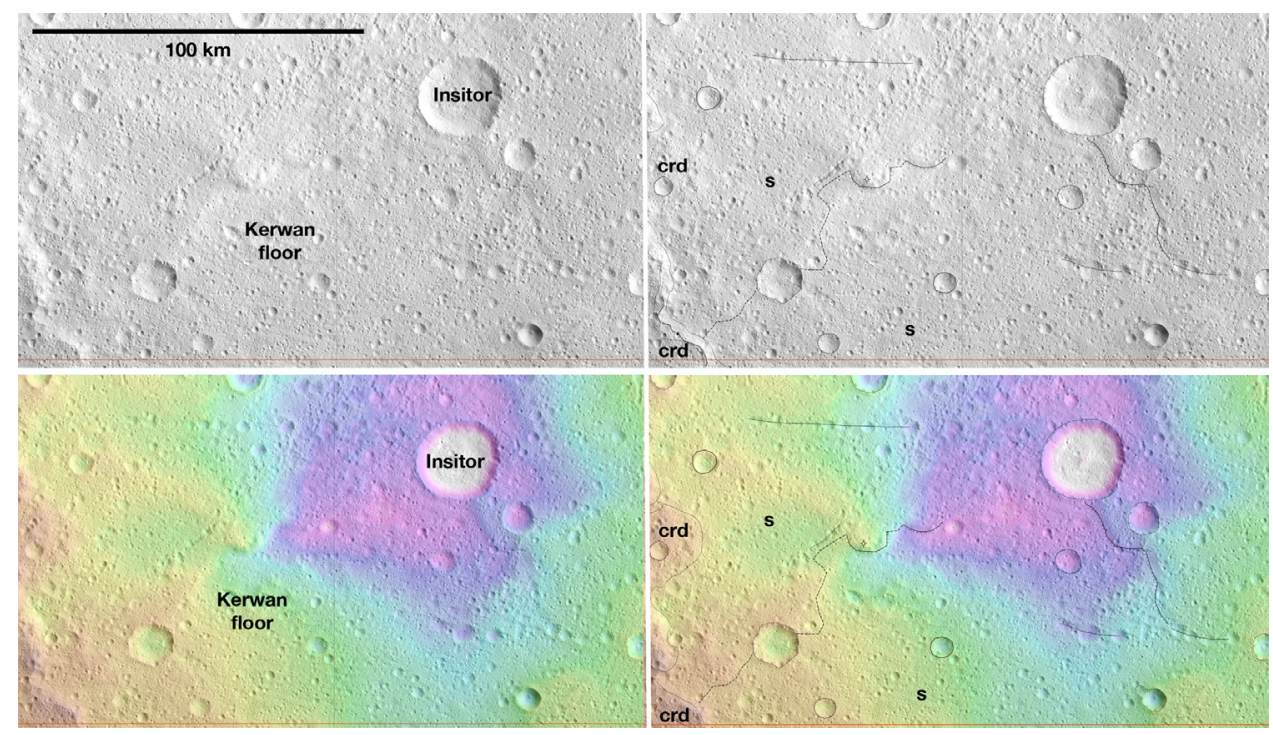

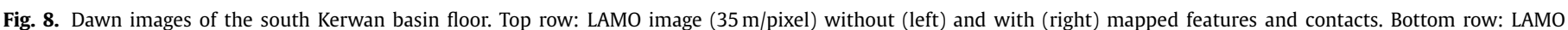

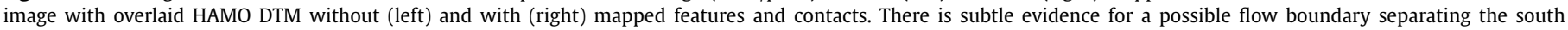
central Kerwan floor from the remainder of the floor.

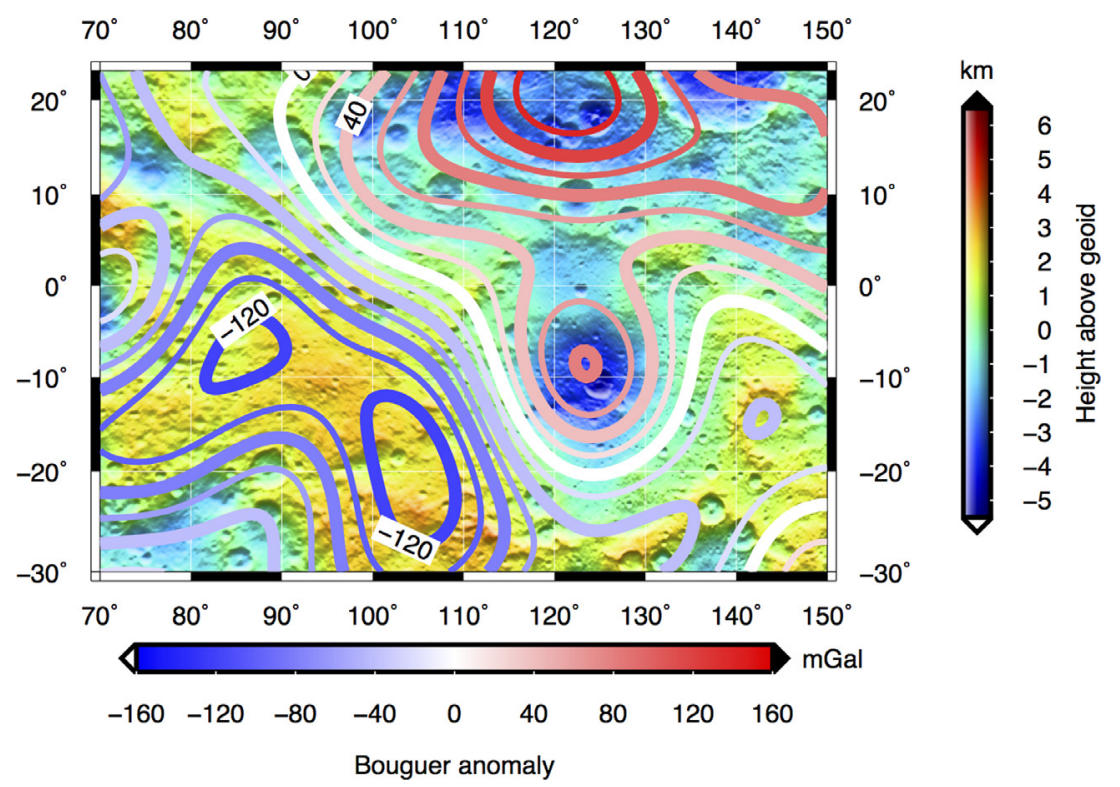

Fig. 9. Dawn gravity map of the Kerwan Quadrangle. Boundaries are $30^{\circ} \mathrm{S}$ to $23^{\circ} \mathrm{N}$ latitude, $70^{\circ}$ to $150^{\circ} \mathrm{E}$ longitude. For more information, see Park et al. (2016).

degraded, transitional complex Rao crater and the 13-km diameter crater Cacaguat, and is suggestive of relative youth. Material extends radially from craters, irregularly, and in linear filaments. Unit displays a higher albedo than Crater material, and is most easily visible in enhanced color and color ratio images. In the color ratio composite, this unit appears light blue-green at Rao and darker blue at Cacaguat, and both stand out from their surroundings. Type area: $8.1^{\circ} \mathrm{N}, 118.9^{\circ} \mathrm{E}$. Interpretation: Rayed impact ejecta of Rao and Cacaguat craters. The blue-green colors in color ratio images are suggestive of a distinct composition or immaturity of the regolith.

\subsubsection{Lobate material (l, RGB color: 0-154-0)}

Description: Unit consists of accumulations of material in lobes trending downslope, or mounds of material on crater floors or other topographic lows, with a confined areal extent. There are no apparent variations in albedo of this unit compared to surrounding units, but some lobate units are associated with blue-cyan colors in the CRC, perhaps indicative of different compositions. Type area: $19.3^{\circ} \mathrm{N}, 97.1^{\circ} \mathrm{E}$. Interpretation: Surface material that has been transported downhill by either mass wasting, impact melt deposition, or ground ice flow (Schmidt et al., 2016).

\subsubsection{Light mantle (stipple pattern) and dark mantle (hachure pattern) materials (Surface features)}

Description: Light Mantle unit consist of high albedo materials and Dark Mantle unit consists of low albedo materials, which are superposed on underlying units such that morphological attributes (e.g., crater features, surface textures) are not obscured. These units are commonly visible in enhanced color or color ratio composite images. Interpretation: Components of impact ejecta from young, fresh craters such as Braciaca (stipple) and Dantu (hachure) that thinly mantles the surface. Cryovolcanic venting could also produce some Mantle material in and around Dantu crater (Kneissl et al., 2016). 


\subsection{Dantu crater description of map units (Kneissl et al., 2016)}

Kneissl et al. (2016) mapped Dantu crater, and they completed the geologic map and a DOMU. For the part of Dantu crater that overlaps into Kerwan Quadrangle, we include below their detailed descriptions and interpretations of those Dantu crater units (refer also to Section 4.1.4).

\subsubsection{Dantu unit: crater floor material (cf, RGB color: 117-38-78)}

Description: Unit of occurs in some of the pristine large impact craters $(>\sim 15 \mathrm{~km})$ and has a relatively smooth appearance compared to the hummocky crater floor material. Large, multikilometer long ridges or peaks are missing. However, the texture is clearly rougher in comparison to the commonly neighboring talus material (ta) and slightly rougher than the surface of the bright crater floor material (cfb). The albedo of unit cf corresponds approximately to the average of the Dantu Quadrangle. In the enhanced color mosaics unit of appears mainly greyish, whereas in the CRC the dominant color is blue/cyan. Furthermore, the occurrence of unit cf mapped on the floor of Dantu crater is characterized by an extensive set of concentric and radial fractures. Type area: $22.5^{\circ} \mathrm{N}, 135.8^{\circ} \mathrm{E}$. Interpretation: We interpret unit of to be mass wasting deposit filling the crater floor after the impact event. In contrast to the hummocky crater floor materials (cfh, cfhb, cfhd) and the terrace materials (ct, ctb), unit cf does not contain coherent slump blocks.

\subsubsection{Dantu unit: dark crater floor material (cfd, RGB color: 43-1-20)}

Description: Unit cfd was mapped in Dantu crater and on the floor of a medium-sized impact crater on the southeastern portion of the ejecta blanket of Dantu crater $\left(11^{\circ} \mathrm{N} / 158.1^{\circ} \mathrm{E}\right)$. The surface of unit cfd within Dantu crater has a similar morphological appearance as the adjacent unit cf on Dantu's floor including superposed crater abundances. Only albedo allows a clear separation of these two units. Type area: $19.6^{\circ} \mathrm{N}, 135.7^{\circ} \mathrm{E}$. Interpretation: We interpret unit cfd to be mass wasting deposit filling the crater floor after the impact event. The relatively low albedo in comparison to unit cf seem to be related to compositional differences of the materials in the subsurface that were excavated during the impact event.

\subsubsection{Dantu unit: hummocky crater floor material (cfh, RGB color:}

\section{7-149-148)}

Description: Unit cfh consists of a rough, hilly surface, containing ridges, peaks, and blocks of variable size. The unit is located on the crater floors and at the transitions between the crater walls and the floors of large pristine impact craters. The albedo of the Hummocky Crater Floor material (cfh) corresponds approximately to the average albedo of the Dantu Quadrangle. In the enhanced color mosaics the material appears brownish to bluish, whereas it looks bluish to brownish in the color ratio map. Type area: $28.7^{\circ} \mathrm{N}$, $140.5^{\circ} \mathrm{E}$. Interpretation: We interpret unit $\mathrm{cfh}$ to be the result of mass wasting processes, in particular mass wasting from the crater walls towards the crater centers. Furthermore, the material seems to be related to unit ct, Crater Terrace material in the Dantu Quadrangle (Kneissl et al., 2016). In particular, we interpret unit cfh to consist of the same material as unit ct. However, the slump blocks that build the terraces of unit ct seem to be less disrupted than the smaller blocks in unit cfh.

\subsubsection{Dantu unit: bright hummocky crater floor material (cfhb, RGB color: 234-197-196)}

Description: Unit cfhb shows an even rougher surface than unit cfh, with slightly larger blocks. The unit is mainly located at the transition between the crater wall and the floor of Dantu crater and in the interior of crater F (Dantu Quadrangle: Kneissl et al., 2016). Similar to unit cfh, the unit contains ridges, peaks and blocks of variable size. However, in the photometrically corrected image mosaics, unit cfhb shows a higher albedo, in particular, on the steep slopes, where fresh material is exposed. Morphologically, the surface of unit cfhb resembles the rough surface of unit cb. Furthermore, the unit contains several localized occurrences of bright material (bright spots), increasing the average albedo of the unit. In the enhanced color mosaics and in the color ratio composite mosaics the material appears brownish to bluish. Type area: $23.9^{\circ} \mathrm{N}$, $97.3^{\circ}$ E. Interpretation: Similar to unit $\mathrm{cfh}$, we interpret unit $\mathrm{cfhb}$ to be the result of mass wasting processes, in particular mass wasting from the crater walls towards the crater centers. Unit cfhb seems to consist of the same material as units cb and ctb (ctb mapped in Dantu Quadrangle only).

\subsubsection{Dantu unit: crater central peak material (ccp, RGB color: 204-68-142)}

Description: Crater Central Peak material was mapped in the center of Dantu crater, but occurs in Kerwan Quadrangle in the center of $\sim 40 \mathrm{~km}$ diameter crater superposed on the Dantu ejecta blanket. Here, the unit consists of a topographic mound in the center of the crater. The unit shows a high albedo similar to the albedo of unit $\mathrm{cfh}$. In the enhanced color mosaics the material appears blue-gray, in the color ratio maps dark blue. Type area: $24.0^{\circ} \mathrm{N}, 138.7^{\circ} \mathrm{E}$. Interpretation: High-albedo material from the subsurface that was uplifted during the formation process of the host crater.

\subsubsection{Dantu unit: talus material (ta, RGB color: 0-76-0)}

Description: Unit ta is characterized by a much smoother appearance than the surrounding units and downslope lineations. Furthermore, it shows a low frequency of superposed impact craters. The unit is located within pristine impact craters directly at the crater walls below the crater rims. More degraded impact craters with less pristine crater rims and accordingly shallower slopes do not show unit ta. In particular at Dantu crater, unit ta contains several small-scale (multi-hundred meter) outcrops of high-albedo material (mapped as bright spots), showing downslope movement of the bright material. Type area: $24.7^{\circ} \mathrm{N}, 145.6^{\circ} \mathrm{E}$. Interpretation: The most likely explanation for the smooth appearance of the surface of unit ta is the influence of gravity-driven mass wasting on slopes. This process continuously erases small impact craters or surface features from slopes and leaves a surface much smoother than the surrounding less steep areas. Downslope lineations might be the result of gravity-driven rockfall or other mass wasting processes.

\subsubsection{Dantu unit: crater material, dark (cd, RGB color 247-247-127)}

Description: Unit consists of a hilly to hummocky surface proximal to and trending away from the Dantu crater rim, with an appearance similar to Crater material (unit "c" ), but with a visibly lower albedo. Unit is located with the range of Dantu's continuous ejecta blanket, and lacks large impact craters ( $>10 \mathrm{~km}$ diameter). Type area: $16.9^{\circ} \mathrm{N}, 132.6^{\circ} \mathrm{E}$. Interpretation: Low albedo crater ejecta from Dantu impact event.

\subsection{Structural features}

Our map region contains a limited variety of structural features. We have mapped crater rims for craters larger than $5 \mathrm{~km}$ diameter, including both well-preserved and degraded rims. We mapped grooves, ridges, scarps and lineaments as well as central peaks of Inamahari, Bonsu, and Tafakula craters. Kneissl et al. (2016) mapped many grooves radial to and within the continuous ejecta blanket of Dantu crater. We mapped a WSWESE-trending groove SE of Tafakula, part of which corresponds to the location of the bright ray from Occator crater mentioned in Section 4.1.3. In that same section we describe a discontinuous scarp and a pit-crater chain that extends from crater Insitor, 
both of which separate the south central part of the Kerwan basin smooth material from the rest of the basin. It remains unclear, at LAMO resolution, whether these structural features actually mark a flow boundary within the basin.

Several craters in this quadrangle have been classified as having polygonal rims (Otto et al., 2016), including Inamahari, Homshuk, Insitor, and Kerwan. However, none of the fragments of Kerwan's degraded rim align with any of our mapped structural features.

\subsection{Insights from VIR}

Both FC and VIR reveal albedo variations in Ceres surface (Nathues et al., 2017), particularly with the bright spots associated with craters (e.g., Occator, Oxo, Haulani). In particular, VIR data show that the larger Vendimia Planitia lowlands region, which contains both the Kerwan Quadrangle and Dantu crater, is the brightest region of Ceres, being about $10 \%$ brighter than the average Ceres surface (Ciarniello et al., 2017). Currently it is unclear why this region of Ceres should be brighter than the remainder of the surface; we speculate that it may have something to do with the Kerwan and Dantu impact events, and any subsequent geologic activity, or the formation of the larger Vendemia Planitia if it was indeed formed by an ancient large impact event (Marchi et al., 2016). The various high-albedo and colored deposits around Dantu could be related to the Dantu event itself, or subsequent cryovolcanic activity (Kneissl et al., 2016).

VIR data also show that the region around the Kerwan smooth material has stronger $\mathrm{Mg}-\mathrm{OH}$ and $\mathrm{NH}_{4}$ band depths (at 2.7 and 3.1 $\mu \mathrm{m}$ ) compared to the nearby regions (Ammannito et al., 2016). Because the band center is almost constant in this quadrant and is similar across the entire Ceres surface, we interpret these data to indicate that there is a higher concentration of phyllosilicates in the Kerwan Quadrangle. In particular, the young fresh rayed crater Rao shows more evidence of ammoniated phyllosilicates than any other surface in the quadrangle. Additionally, the low-albedo area located southwest of the Dantu crater, corresponding to the dark crater material unit, is volatile poor. This area, which is depleted in $\mathrm{OH}$ and $\mathrm{NH}_{4}$, extends to the northeast onto the hummocky crater floor material of Dantu (Ammannito et al., 2016).

\subsection{Geologic synthesis}

\subsubsection{Kerwan impact basin and smooth terrain}

Previous morphological analysis suggested that Kerwan is the oldest, largest unequivocal impact crater on Ceres. As was reported in Hiesinger et al. (2016), the subdued rim, the gently-sloped smooth floor, the lack of a central peak, and the lower crater density compared to the surrounding terrain suggests that viscous relaxation of a moderately ice-bearing crust (see also Bland et al., 2016) had some role in the evolution of the basin, which has implications for the evolution of Ceres' crust and interior. The Dawn gravity data are also consistent with the interpretation of significant amounts of ice in the crust at the time and location of the Kerwan impact (i.e., $<30-40 \%$ ).

What is the origin of the Kerwan Smooth material? Individual hypotheses include ballistic emplacement of a volatile-rich ejecta blanket, surficial flows of volatile-rich impact melts, cryovolcanic flows, ground ice flows, or mass wasting deposits. We discount mass wasting because the smooth material occurs on both topographically high and low areas, such that gravitationally induced movement down slope is unlikely. Our analysis and mapping of the basin floor and surrounding smooth materials show no evidence of lobate flow margins typical of putative ground ice flows observed in other quadrangles (e.g., Schmidt et al., 2017; Hughson et al., 2017; this issue). Likewise, we observe no cryovolcanic vents (either point or fissure source), although if they existed they could be buried. There are no features that look like lava flows or impact melt flows either inside or outside the Kerwan basin. The arcuate scarps that could be a putative flow boundary within the basin floor remains equivocal given the spatial resolution of the available images. Thus we favor the interpretation of the Kerwan Smooth material as impact-induced melting and transport of a volatile-bearing crust and emplacement of a volatile-rich ejecta blanket soon after the Kerwan impact event, that has degraded by subsequent space weathering, micrometerorite bombardment and larger impact events.

Hiesinger et al. (2016) originally reported model ages for the Kerwan smooth terrain, based on HAMO images at $140 \mathrm{~m} /$ pixel, of $0.72 \mathrm{Ga}(\mathrm{LDM})$ and $0.55 \mathrm{Ga}(\mathrm{ADM})$. Our geological mapping and application of crater statistics using LAMO images at $35 \mathrm{~m} /$ pixel of the portion of the Kerwan smooth terrain within the Kerwan Quadrangle gives ages of $\sim 1.3 \mathrm{Ga}$ (LDM) and $\sim 0.23-0.85 \mathrm{Ga}$ (ADM, modified from that described in Hiesinger et al. (2016), that considers strength of target material). This singular unit provides a marker for youngest age of the Kerwan impact, which is older than the corresponding absolute model ages of other major craters and basins on Ceres (see e.g., discussion of ages of the Urvara and Yalode impacts: Crown et al. (2017; this issue); Occator: Buczkowski et al. (2017; this issue); Haulani: Krohn et al. (2017; this issue). Note however that work is continuing on the evalua-
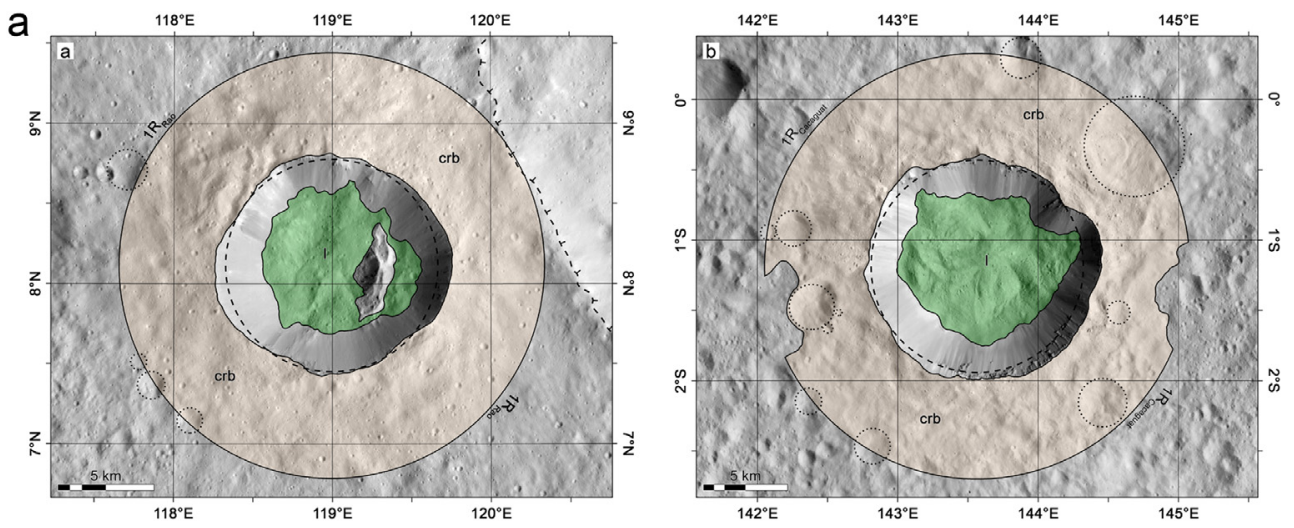

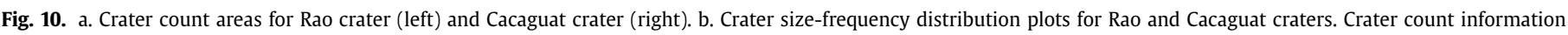

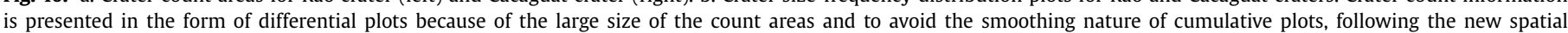

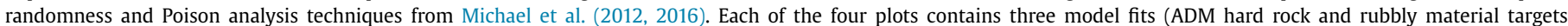

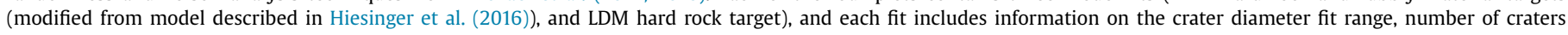
counted, model age with error bars, and cumulative N(1) value. See also Table 1. 


\section{b}
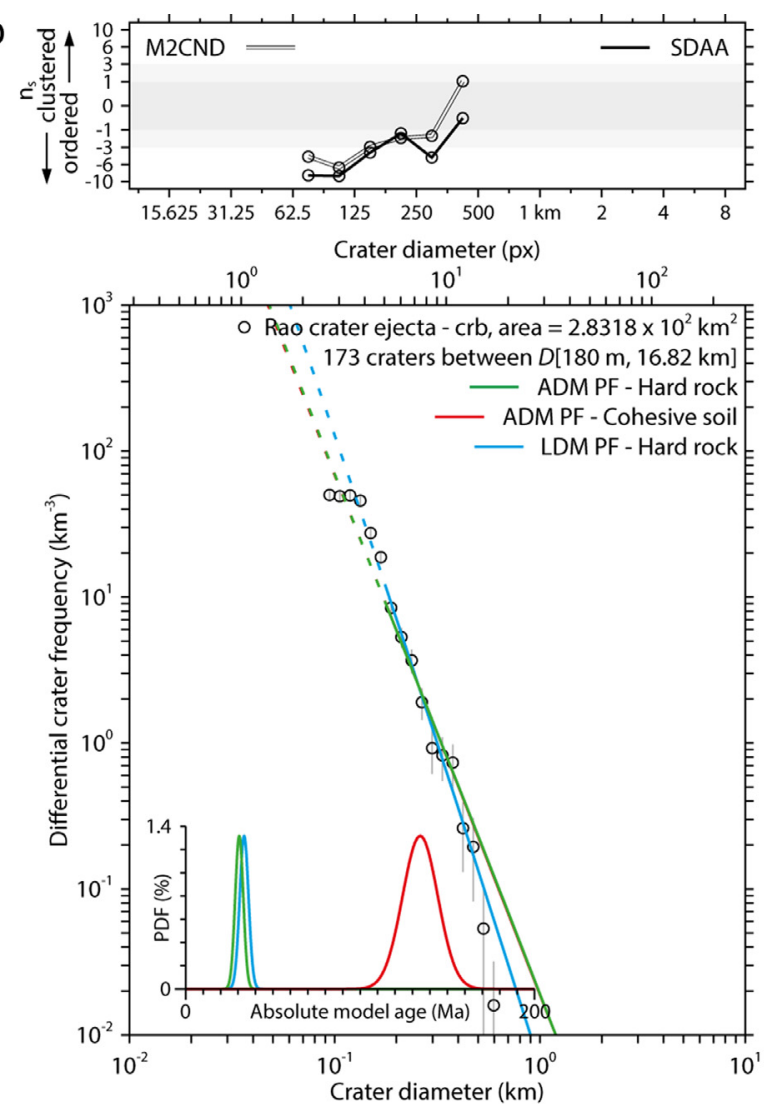

Crater diameter (km)
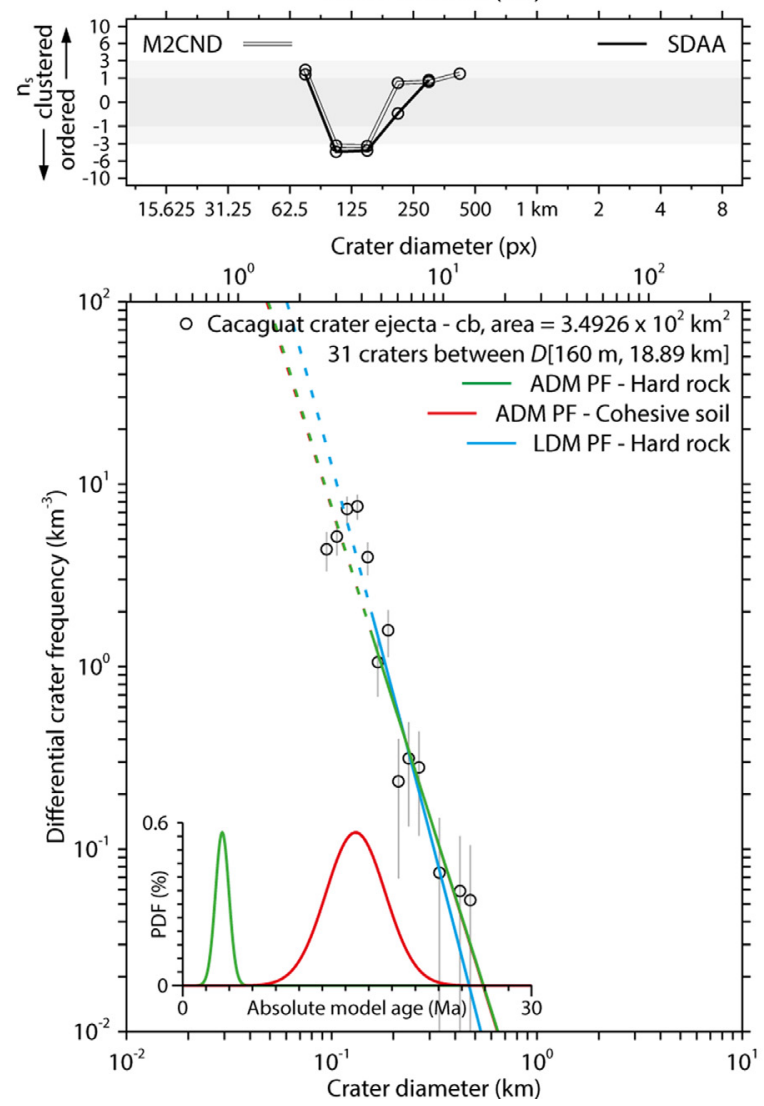
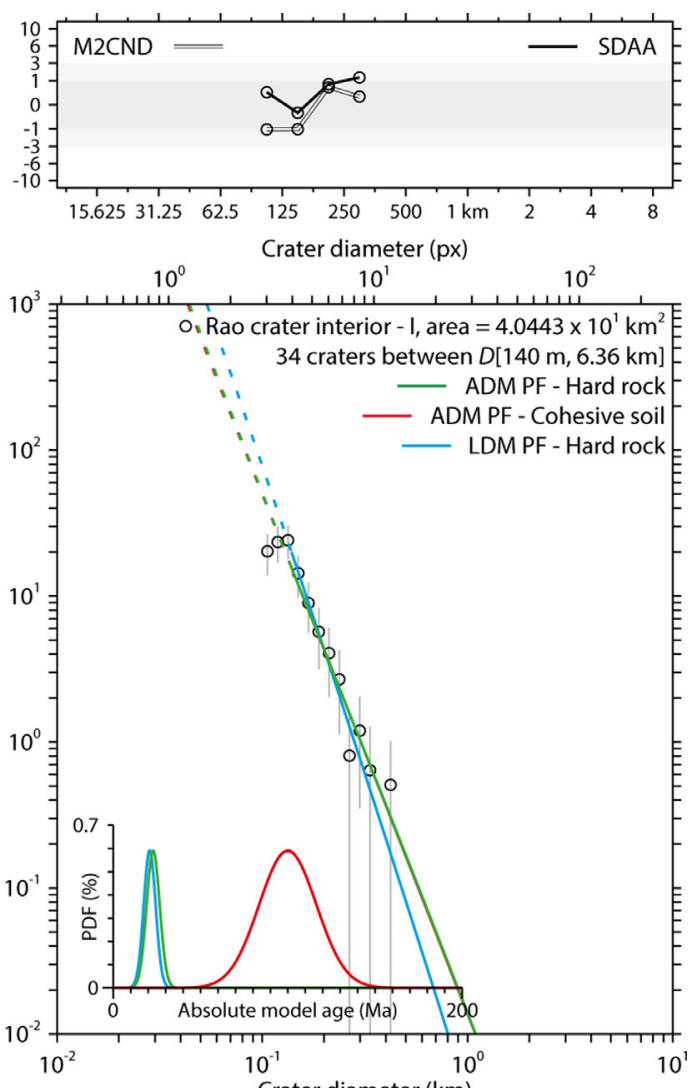

Crater diameter $(\mathrm{km})$
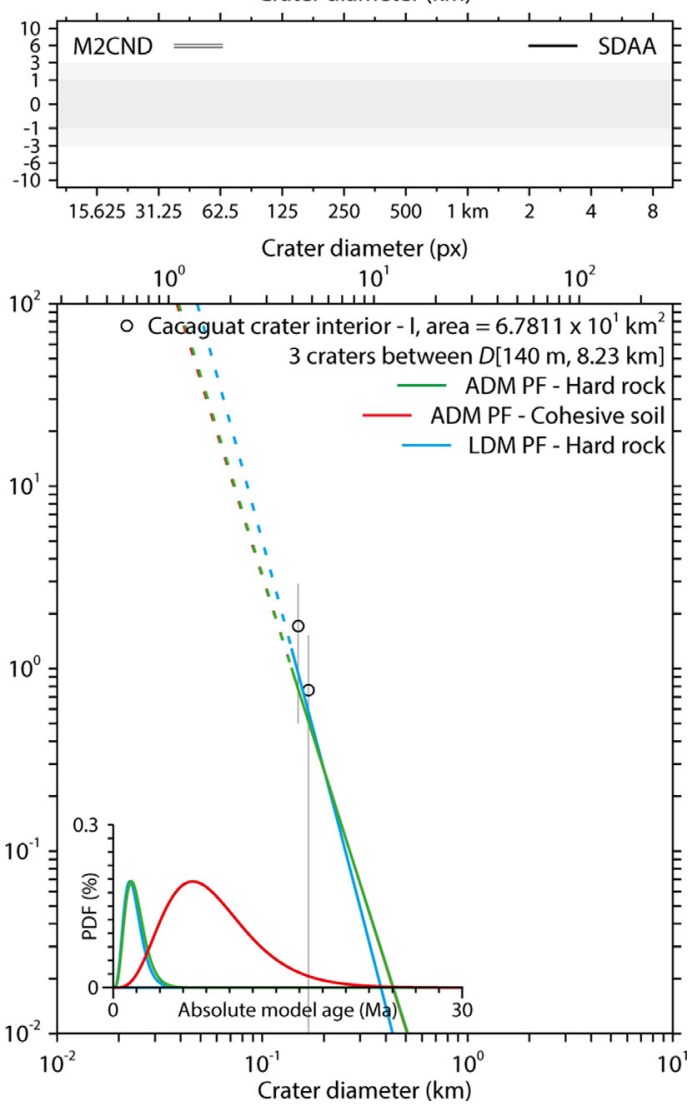

Fig. 10. Continued 


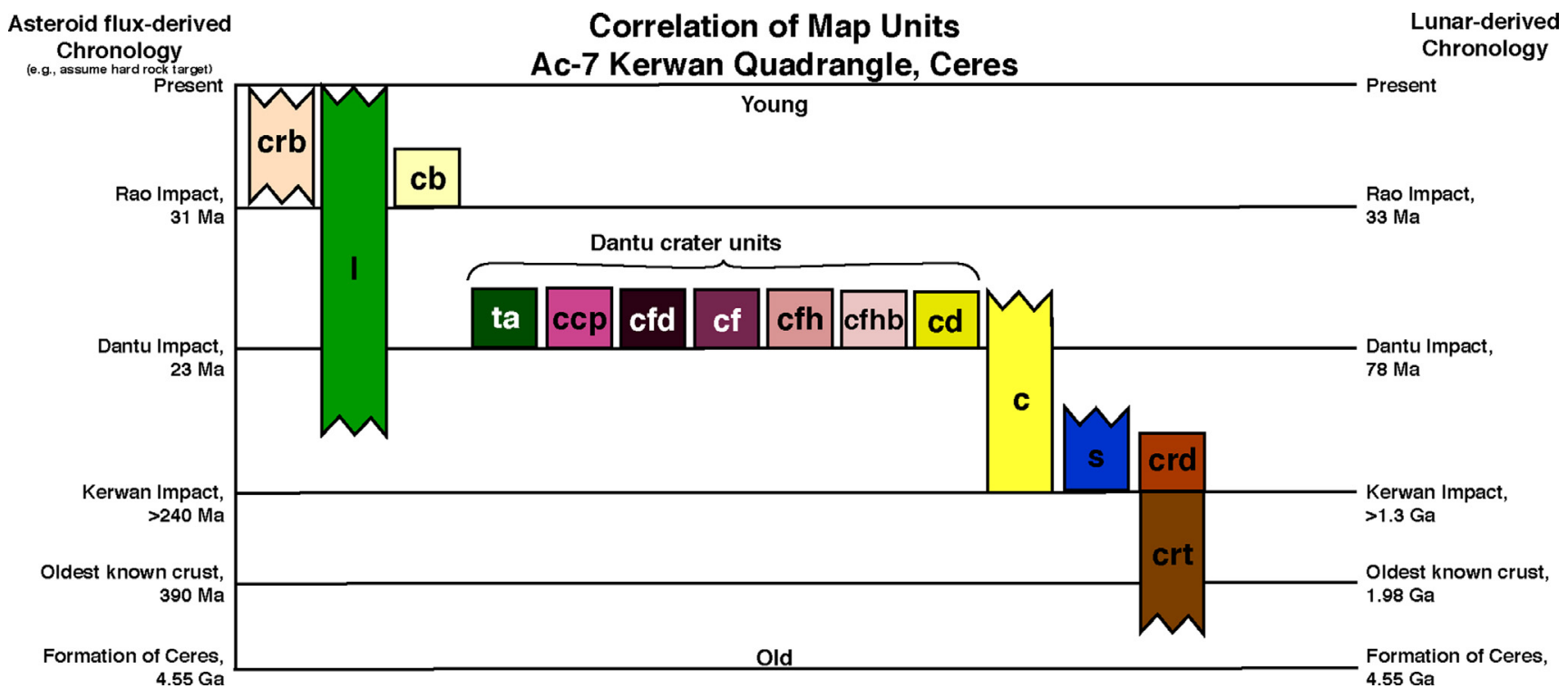

Fig. 11. Correlation of Map Units (COMU) for the Ac-7 Kerwan Quadrangle geologic map in Fig. 3a.

tion of model ages for Ceres geologic units (see e.g., Neesemann et al., 2017; in preparation), and more definitive model ages for Ceres chronostratigraphic units will be reported in the global mapping paper by S.C. Mest et al. (in preparation).

\subsubsection{Dantu crater}

The complete Dantu crater geological map is included as a supplement in the Introductory paper and was discussed in Kneissl et al. (2016), so here we make a few points about Dantu that are relevant to the Kerwan map region. Dantu crater materials clearly overlie Kerwan ejecta (unit $s$ ) to the north of the basin, which marks Dantu as stratigraphically younger. This is confirmed by AMAs from crater counts: $77.7 \pm 8.0 \mathrm{Ma}(\mathrm{LDM})$ and $22.9 \pm 2.3$ Ma (ADM). The portion of the Dantu crater floor in the Kerwan Quadrangle displays a variety of crater wall, floor, and ejecta units, as well as floor fractures, and diffuse mantling materials. The variety of colored deposits in and around Dantu crater suggests excavation of a heterogeneous crust by the impact (Kneissl et al., 2016).

\subsubsection{Younger features}

Several examples of lobate materials occur in Kerwan Quadrangle, mostly on the floors of craters, but one example on the southern downslope side of a crater just outside the quadrangle, north of crater Homshuk $\left(20^{\circ} \mathrm{N}, 96^{\circ} \mathrm{E}\right.$, see Lobate material type example in Fig. 4), is distinctive. It is morphologically reminiscent of impact melt flows seen on the Moon (e.g., Wilhelms, 1987). Ceres has a wide variety of lobate flows, possibly produced by mass wasting, impact melt, cryovolcanic flows, or ground ice movement (see e.g., Schmidt et al., 2017; Hughson et al., 2017; this issue).

The bright-rayed impact craters Rao and Cacaguat stand out in FC color data, and are superposed upon both Dantu and Kerwan materials, suggesting they are the youngest features in this region. Crater counts of the Rao rayed ejecta provide an AMA of $33.2 \pm 2.5 \mathrm{Ma}(\mathrm{LDM})$ and $30.1 \pm 2.3 \mathrm{Ma}$ to $133 \pm 10 \mathrm{Ma}(\mathrm{ADM})$, whereas crater counts of the Cacaguat ejecta provide an AMA of $3.3 \pm 0.6 \mathrm{Ma}(\mathrm{LDM})$ and $3.3 \pm 0.6 \mathrm{Ma}$ to $14.4 \pm 2.6 \mathrm{Ma}(\mathrm{ADM})$ (Fig. 10, Table 1). These ages compare favorably to other rayed craters on Ceres: Haulani ejecta (1.67 Ma (ADM), 1.96 Ma (LDM), Krohn et al., 2017; this issue); Occator ejecta ( 14.3 Ma (ADM), $\sim 31.8 \mathrm{Ma}$ (LDM, Neesemann et al., 2017; in preparation). As on the Moon (Wilhelms, 1987), rayed craters mark the youngest geologic features on Ceres.

\section{Geologic history of Kerwan quadrangle, and relation to Ceres geologic time scale}

Our geologic mapping enables recognition of the geologic history of the Kerwan Quadrangle and surrounding region. Fig. 11 shows the correlation of map units from our geological map. The oldest unit is the Cratered terrain, and crater counts show that this unit extends back to $\sim 2$ Ga (LDM) or 0.39$1.03 \mathrm{Ga}$ (ADM, depending on strength of target material) in this quadrangle. The Kerwan impact and subsequent formation of the Smooth material (whether within or outside the basin) occurred $\sim 1.3 \pm 0.22 \mathrm{Ga}$ (LDM) or $\sim 0.23 \pm 0.028$ to $0.85 \pm 0.051 \mathrm{Ga}$ (ADM, depending on strength of target material). We note that these ages are older than those obtained from counts of parts of the ejecta blankets of the Urvara and Yalode impact basins in the southern hemisphere (Crown et al., 2017; this issue). However, Kerwan and Urvara-Yalode basins are sufficiently separated geographically such that clear cross-cutting relationships between these basins have not been recognized. The next major event to affect the Kerwan Quadrangle was the Dantu impact, which occurred $~ 78$ Ma (LDM) or $\sim 23 \mathrm{Ma}$ (ADM). Younger, rayed craters such as Rao and Cacaguat mark the youngest events in the Kerwan Quadrangle, in which Rao formed no later than $\sim 33-34$ Ma and Cacaguat formed $\sim 3.3-3.6$ Ma (both chronologies).

Our work helps us define the base of the cerean geologic timescale. We recognize the Kerwan impact event as the oldest regional to global event on Ceres, which defines the first, oldest boundary of the timescale (Mest et al., 2017b, in preparation). We define the "Pre-Kerwanan" Period and the "Kerwanan" Period, based on the Kerwan impact event, which our crater counts show no later than the formation of the Kerwan smooth materials, $\sim 1.3$ Ga (LDM) or $\sim 0.23-0.85$ Ga (ADM, depending on strength of target material). Regardless of the differences in AMAs from the two chronology systems, the relative stratigraphy is consistent; from oldest to youngest, the major events in the Kerwan region are: Formation of cratered terrain, Kerwan impact event, Dantu impact event, Rao impact event Cacaguat impact event. Note, however, that Ceres crater statistics are continuing to be refined as of this writing, and that the Team's consensus model ages for Ceres chronostratigraphy and geologic time scale will be reported in the HAMO-based global geologic map paper by Mest et al. (in preparation). 


\section{Conclusions}

We constructed a geological map of the Ac-7 Kerwan Quadrangle of dwarf planet Ceres, and surrounding areas, to determine the geological history of the Kerwan impact basin region. We used imaging, spectral, and gravity data from NASA's Dawn mission to investigate the geological evolution of this region. The 284$\mathrm{km}$ diameter Kerwan basin is the oldest, largest undisputed impact crater on Ceres, with a discontinuous, polygonal, heavily degraded rim surrounding a shallow interior containing a smooth material that extends outside the basin to the west, south, and east. There is no unequivocal evidence for cryovolcanic activity in or around the Kerwan basin, and we interpret the smooth material as formed from impact-induced melting of an ice-rich cerean crust, or alternatively is some form of volatile-rich ejecta. Our crater counts of the smooth material suggest the Kerwan basin formed no later than $\sim 1.3 \mathrm{Ga}$ (LDM) or $\sim 0.23-0.85 \mathrm{Ga}$ (ADM, depending on strength of target material), suggesting that there was still a significant component of ice in the crust at this location on Ceres at the time of basin formation. Bland et al. (2016) suggest Ceres has $<30 \%-40 \%$ ice in its crust globally at present. From our mapping, future modeling work should address whether this amount of crustal ice could be melted to produce a deposit like the Kerwan Smooth material, or whether there could have been a great local concentration of ice in this region. Nevertheless, our mapping study supports the development of the cerean geologic timescale, in which we can define the "Pre-Kerwanan" and "Kerwanan" Periods separated by the Kerwan impact event, as the oldest major unequivocal geologic event on Ceres.

\section{Acknowledgments}

The authors thank David Crown and Tracy Gregg, and editor Michael Bland for productive and helpful reviews. The authors also thank the NASA Dawn Science and Flight Teams at the Jet Propulsion Laboratory for their tireless work that enabled the successful Ceres mission, and the instrument teams at the Max Planck Institute for Solar System Research, the German Aerospace Center (DLR), the Italian National Institute of Astrophysics (INAF), and the Planetary Science Institute for collecting and processing the data that enabled this study. The funding for this research was provided under NASA contract NNM05AA86 through a subcontract from the University of California, Los Angeles. The VIR Team is funded by the Italian Space Agency (ASI) through grant number I/004/12/0. We acknowledge the support of the Ronald Greeley Center for Planetary Studies, the NASA Regional Planetary Information Facility (RPIF) at ASU, without which this research could not have been done.

\section{Supplementary material}

Supplementary material associated with this article can be found, in the online version, at doi:10.1016/j.icarus.2017.08.015.

\section{References}

Ammannito, E., DeSanctis, M.C., Ciarniello, M., Frigeri, A., Carrozzo, F.G., -Ph Combe, J., Ehlmann, B.L., Marchi, S., McSween, H.Y., Raponi, A., Toplis, M., Tosi, F., Castillo-Rogez, J.C., Capaccioni, F., Capria, M.T., Fonte, S., Giardino, M., Jaumann, R., Longobardo, A., Joy, S.P., Magni, G., McCord, T.B., McFadden, L.A., Palomba, E., Pieters, C.M., Polanskey, C.A., Rayman, M.D., Raymond, C.A., Schenk, P., Zambon, F., Russell, C.T., the Dawn Science Team, 2016. Distribution of phyllosilicates on Ceres. Science 353. doi:10.1126/science.aaf4279.

Bland, M.T., Raymond, C.A., Schenk, P.M., Fu, R.R., Kneissl, T., Pasckert, J.H., Hiesinger, H., Preusker, F., Park, R.S., Marchi, S., King, S.D., Castillo-Rogez, J.C., Russell, C.T., 2016. Composition and structure of the shallow subsurface of Ceres revealed by crater morphology. Nat. Geosci. 9, 538-543.
Buczkowski, D.L., Schmidt, B., Williams, D.A., Mest, S.C., Scully, J.E.C., Ermakov, A.I., Preusker, F., Schenk, P., Otto, K.A., Hiesinger, H., O'Brien, D., Marchi, S., Sizemore, H., Hughson, K., Chilton, H., Bland, M., Byrne, S., Schorghofer, N., Platz, T. Jaumann, R., Roatsch, T., Sykes, M.V., Nathues, A., De Sanctis, M.C., Raymond, C.A., Russell, C.T., 2016. The geomorphology of Ceres. Science 353. doi:10. 1126/science.aaf4332.

Buczkowski, D.L., Williams, D.A., Scully, J.E.C., Mest, S., Crown, D.A., Schenk, P., Jaumann, R., Roatsch, T., Preusker, F., Platz, T., Nathues, A., Hoffmann, M., Schaefer, M., Marchi, S., De Sanctis, M.C., Raymond, C., Russell, C., 2017. The geology of the Occator quadrangle of dwarf planet Ceres: floor-fractured craters and other geomorphic evidence of cryomagmatism. Icarus, this issue.

Ciarnello, M., De Sanctis, M.C., Ammannito, E., Raponi, A., Longobardo, A., Palomba, E., Carrozzo, F.G., Tosi, F., Li, J.-Y., Schröder, S.E., Zambon, F., Frigeri, A., Fonte, S., Giardino, M., Pieters, C.M., Raymond, C.A., Russell, C.T., 2017. Spectrophotometric properties of dwarf planet Ceres from the VIR spectrometer on board the Dawn Mission. Astron. Astrophys. 598, \#A130. doi:10.1051/004-6361/ 201629490.

Crown, D.A., Sizemore, H., Aileen Yingst, R., Mest, S., Platz, T., Berman, D., Schmedemann, N., Buczkowski, D., Williams, D.A., Roatsch, T., Preusker, F., Raymond, C. Russell, C., 2017. Geologic mapping of the Urvara and Yalode Quadrangles, Ceres. Icarus, this issue.

De Sanctis, M.C., Coradini, A., Ammannito, E., Filacchione, G., Capria, M.T., Fonte, S., Magni, G., Barbis, A., Bini, A., Dami, M., Ficai-Veltroni, I., Preti, G.VIR Team, 2011 The VIR spectrometer. Space Sci. Rev. 163, 329-369.

De Sanctis, M.C., Ammannito, E., Raponi, A., Marchi, S., McCord, T.B., McSween, H.Y. Capaccioni, F., Capria, M.T., Carrozzo, F.G., Ciarniello, M., Longobardo, A., Tosi, F., Fonte, S., Formisano, M., Frigeri, A., Giardino, M., Magni, G., Palomba, E., Turrini, D., Zambon, F., Combe, J.-P., Feldman, W., Jaumann, R., McFadden, L.A. Pieters, C.M., Prettyman, T., Toplis, M., Raymond, C.A., Russell, C.T., 2016. Ammoniated phyllosilicates with an outer solar system origin on (1) Ceres. Nature 528, 241-244.

Ermakov, A.I., Fu, R.R., Castillo-Rogez, J.C., Raymond, C.A., Park, R.S., Preusker, F., Russell, C.T., Smith, D.E., Zuber, M.T., 2017. Constraints on Ceres' internal structure and evolution from its shape and gravity measured by the Dawn spacecraft. J. Geophys. Res. in review.

Hiesinger, H., Marchi, S., Schmedemann, N., Schenk, P., Pasckert, J.H., Neesemann, A., O'Brien, D.P., Kneissl, T., Ermakov, A.I., Fu, R.R., Bland, M.T., Nathues, A., Platz, T., Williams, D.A., Jaumann, R., Castillo-Rogez, J.C., Ruesch, O., Schmidt, B., Park, R.S., Preusker, F., Buczkowski, D.L., Russell, C.T., Raymond, C.A., 2016. Cratering on Ceres: implications for its crust and evolution. Science 353. doi:10. 1126/science.aaf4759.

Hughson, K., Buczkowski, D., Mest, S., Scully, J.E.C., Combe, J-Ph., Platz, T., Ruesch, O., Preusker, F., Jaumann, R., Nass, A., Roatsch, T., Nathues, A., Schaefer, M., Schmidt, B., Chilton, H., Ermakov, A., McFadden, L., Russell, C., Williams, D.A. Pasckert, J.H., 2017. The Ac-H-5 (Fejokoo) Quadrangle of Ceres: Geologic map and geomorphological evidence for ground ice mediated surface processes. Icarus, this issue.

Kneissl, T., Schmedemann, N., Neesemann, A., Williams, D.A., Crown, D.A., Mest, S.C. Buczkowski, D.L. Scully, J.E.C., Frigeri, A., Ruesch, O, Hiesinger, H., Walter, S.H.G. Jaumann, R., Roatsch, T., Preusker, F., Kersten, E., Nass, A., Nathues, A., Platz, T., Hoffmann, M., Schaefer, M., De Sanctis, M.C., Raymond, C.A., Russell, C.T., 2016. Geologic mapping of the Ac-H-3 Dantu Quadrangle of Ceres from NASA's Dawn mission. 47th Lun. Planet. Sci. Conf.. Lunar and Planetary Institute, Houston Abstract \#1967.

Konopliv, A.S., Park, R., Vaughn, A., Bills, B., Asmar, S., Ermakov, A., Rambaux, N., Raymond, CA., Castillo, J., Russell, CT. Smith, D., Zuber, M., 2017. The Ceres gravity field, spin pole, rotation period and orbit from the Dawn radiometric tracking and optical data. Icarus, in review.

Krohn, K., Jaumann, R., Otto, K.A., Schulzeck, F., Neesemann, A., Nass, A, Stephan, K., Tosi, F., Wagner, R.J., Zambon, F., von der Gathen, I., Williams, D.A. Buczkowski, D.L., De Sanctis, M.C., Kersten, E., Matz, K.-D., Mest, S.C., Pieters, C.M., Preusker, F., Roatsch, T., Scully, J.E.C., Russell, C.T., Raymond, C.A. 2017. The unique geomorphology and structural geology of the Haulani crater of dwarf planet Ceres as revealed by geological mapping of equatorial Quadrangle Ac-6 Haulani. Icarus, this issue.

Küppers, M., O’Rourke, L., Bockelee-Morvan, D., Zakharov, V., Lee, S., von Allmen, P., Carry, B., Teyssier, D., Marston, A., Müller, T., Crovisier, J., Barucci, M.A., Moreno, R., 2014. Localized sources of water vapour on the dwarf planet (1) Ceres. Nature 505, 525-527.

Marchi, S., Ermakov, A.I., Raymond, C.A., Fu, R.R., O’Brien, D.P., Bland, M.T., Ammannito, E., De Sanctis, M.C., Bowling, T., Schenk, P., Scully, J.E.C., Buczkowski, D.L., Williams, D.A., Hiesinger, H., Russell, C.T., 2016. The missing large impact craters on Ceres. Nat. Comm. doi:10.1038/ncomms12257.

Mest, S.C., Crown, D.A., Yingst, R.A., Berman, D.C., Williams, D.A., Buczkowski, D.L., Scully, J.E.C., Platz, T., Jaumann, R., Roatsch, T., Preusker, F., Nathues, A., Hiesinger, H., Pasckert, J.H., Raymond, C.A., Russell, C.T.the Dawn Science Team, 2017a. The global geologic map of Ceres based on Dawn HAMO observations. 48th Lunar Planet. Sci. Conf.. Lunar and Planetary Institute, Houston Abstract \#2512.

Mest, S.C., Crown, D.A., Yingst, R.A., Berman, D.C., Williams, D.A., Buczkowski, D.L, Scully, J.E.C., Platz, T., Jaumann, R., Roatsch, T., Preusker, F., Nathues, A., Hiesinger, H., Pasckert, J.H., Raymond, C.A., Russell, C.T., 2017b. The global geologic map of Ceres based on Dawn HAMO observations. Icarus, in preparation. 
Michael, G.G., Platz, T., Kneissl, T., Schmedemann, N., 2012. Planetary surface dating from crater size-frequency distribution measurements: spatial randomness and clustering. Icarus 218, 169-177. doi:10.1016/j.icarus.2011.11.033.

Michael, G.G., Kneissl, T., Neesemann, A., 2016. Planetary surface dating from crater size-frequency distribution measurements: Poisson timing analysis. Icarus 277, 279-285. doi:10.1016/j.icarus.2016.05.019.

Neesemann, A., Schmedemann, N., van Gasselt, S., Walter, S.H.G., Michael, G.G., Preusker, F., Hiesinger, H., Jaumann, R., Roatsch, T., Raymond, C.A., Russell, C.T., 2017. A comprehensive analysis of the spatial crater density variation at Occator crater, Ceres, and implications for absolute model age estimates. Icarus, in preparation.

Otto, K.A., Jaumann, R., Krohn, K., Buczkowski, D.L., von der Gathen, I., Kersten, E., Mest, S., Nass, A., Neesemann, A., Preusker, F., Roatsch, T., Schröder, S.E., Schulzeck, F., Scully, J.E.C., Stephan, K., Wagner, R., Williams, D.A., Raymond, C.A., Russell, C.T., 2016. Origin and distribution of polygonal craters on (1) Ceres. 47th Lunar Planet. Sci. Conf.. Lunar and Planetary Institute, Houston Abstract \#1493.

Park, R.S., Konopliv, A.S., Bills, B.G., Rambaux, N., Castillo-Rogez, J.C., Raymond, C.A., Vaughan, A.T., Ermakov, A.I., Zuber, M.T., Fu, R.R., Toplis, M.J., Russell, C.T., Nathues, A., Preusker, F., 2016. A partially differentiated interior for (1) Ceres deduced from its gravity field and shape. Nature 537, 515-517. doi:10.1038/ nature 18955

Prettyman, T., Feldman, W.C., McSween Jr., H.Y., Dingler, R.D., Enemark, D.C., Patrick, D.E., Storms, S.A., Hendricks, J.S., Morgenthaler, J.P., Pitman, K.M., Reedy, R.C., 2011. Dawn's Gamma Ray and Neutron detector. Space Sci. Rev. 163, 371-459.

Preusker, F., Scholten, F., Matz, K.-D., Elgner, S., Jaumann, R., Roatsch, T., Joy, S.P., Polansky, C.A., Raymond, C.A., Russell, C.T., 2016. Dawn at Ceres - shape model and rotational state. 47th LPSC. Lunar and Planetary Institute, Houston Abstract \#1954.
Roatsch, T., Kersten, E., Matz, K.-D., Preusker, F., Scholten, F., Jaumann, R., Raymond, C.A., Russell, C.T., 2016. High-resolution Ceres high altitude mapping orbit atlas derived from Dawn Framing Camera images. Planet. Space Sci. 129, 103-107.

Russell, C.T., 20 coauthors, 2004. Dawn: a journey in space and time. Planet. Space Sci. 52, 465-489.

Schmidt, B.E., Hughson, K.G., Chilton, H.T., Scully, J.E.C., Platz, T., Nathues, A., Sizemore, H., Bland, M.T., Byrne, S., Marchi, S., O'Brien, D.P., Schorghofer, N., Hiesinger, H., Jaumann, R., Lawrence, J., Buczowski, D., Castillo-Rogez, J.C., Sykes, M.V., Schenk, P.M., DeSanctis, M.C., Mitri, G., Formisano, M., Li, J-Y, Reddy, V., LeCorre, L., Russell, C.T., Raymond, C.A.the Dawn Science and Operations Teams, 2016. Ground ice on Ceres? 47th LPSC. Lunar and Planetary Institute, Houston Abstract \#2677.

Schmidt, B.E., Hughson, K.G., Chilton, H.T., Scully, J.E.C., Platz, T., Nathues, A., Sizemore, H., Bland, M.T., Byrne, S., Marchi, S., O'Brien, D.P., Schorghofer, N., Hiesinger, H., Jaumann, R., Pasckert, J.H., Lawrence, J.D., Buczowski, D., CastilloRogez, J.C., Sykes, M.V., Schenk, P.M., DeSanctis, M.C., Mitri, G., Formisano, M., Li, J-Y, Reddy, V., LeCorre, L., Russell, C.T., Raymond, C.A., 2017. Geomorphological evidence for ground ice on dwarf planet Ceres. Nat. Geo. doi:10.1038/ NGEO2936.

Sierks, H., Keller, H.U., Jaumann, R., Michalik, H., Behnke, T., Bubenhagen, F., Büttner, I., Carsenty, U., Christensen, U., Enge, R., Fiethe, B., Gutierrez Marques, P., Hartwig, H., Kühne, H., Maue, T., Mottola, S., Nathues, A., Reiche, K.-U., Richards, M.L., Roatsch, T., Schröder, S.E., Szemerey, I., Tschentscher, M., 2011. The Dawn Framing Camera. Space Sci. Rev. 163, 263-327.

Wilhelms, D.E., 1987. The Geologic History of the Moon. U.S. Geol. Surv. Prof. Pap. 1348. U.S. Government Printing Office, Washington.

Williams, D.A., Buczkowski, D.L., Mest, S.C., Scully, J.E.C., 2017. Introduction: the geologic mapping of Ceres. Icarus, this issue. 